\title{
Le dépôt de poteries gauloises du sanctuaire laténien de Parc-ar-Groas à Quimper (Finistère)
}

The Gallic pottery hoard of the Latenian sanctuary of Parc-ar-Groas in Quimper El depósito de cerámica gala del santuario latino de Parc-ar-Groas en Quimper (Finistère)

Jean-François Villard et Jean-Paul Le Bihan

\section{OpenEdition}

\section{Journals}

Édition électronique

URL : https://journals.openedition.org/rao/7204

DOI : 10.4000/rao.7204

ISSN : $1775-3732$

Éditeur

Presses universitaires de Rennes

Édition imprimée

Date de publication : 21 décembre 2021

Pagination : 139-169

ISBN : 978-2-7535-8668-0

ISSN : 0767-709X

\section{Référence électronique}

Jean-François Villard et Jean-Paul Le Bihan, « Le dépôt de poteries gauloises du sanctuaire laténien de Parc-ar-Groas à Quimper (Finistère) », Revue archéologique de l'Ouest [En ligne], 37 | 2021, mis en ligne le 21 décembre 2021, consulté le 10 octobre 2022. URL : http://journals.openedition.org/rao/ 7204 ; DOI : https://doi.org/10.4000/rao.7204 


\title{
Le dépôt de poteries gauloises du sanctuaire laténien de Parc-ar-Groas à Quimper (Finistère)
}

\author{
The Gallic pottery hoard of the Latenian sanctuary of Parc-ar-Groas in Quimper
}

\author{
Jean-François Villard \\ Inrap Grand-Ouest, Centre de recherche archéologique du Finistère, 91 résidence de Ker Vihan, 29170 Fouesnant (jean-francois.villard@inrap.fr) \\ Jean-Paul Le Bihan \\ Centre de recherche archéologique du Finistère, UMR 6566 CReAAH
}

\begin{abstract}
Résumé : Mis au jour en 1990, le dépôt de poteries gauloises du sanctuaire quimpérois de Parc-ar-Groas demeure inédit, les nombreuses publications concernant ce site traitant essentiellement de son développement au cours de la période gallo-romaine. Une trentaine de profils complets de petits pots et de jattes purent être reconstitués à côté de restes de plus d'une centaine de récipients. Tous proviennent du comblement d'un segment d'un même fossé. Cette concentration de nombreux vases, caractérisée par leur faible contenance, offre un bel échantillonnage de ces récipients en usage à la fin de La Tène finale. Par leur typologie, ils ne differrent pas de ceux des sites d'habitats environnants, mais le catalogue très restreint des formes paraît correspondre à une vaisselle à usage spécifique. Cela ouvre des perspectives et suscite des questions quant à leur utilisation dans le cadre d'activités rituelles sur le site (libations, offrandes).
\end{abstract}

Abstract: The Iron Age pottery deposit uncovered in 1990 at the Parc-ar-Groas sanctuary in Quimper has remained unpublished, the numerous published papers relating to the site mainly focussing on its development during the Roman period. Thirty complete small jars and bowls profiles could be reconstructed from an assemblage one hundred vessels. All were recovered from the fill of a single ditch section. The concentration of numerous vessels, characterised by their low capacity, provide a good sample of this type of vessels used at the end of the Late La Tène period. Their typology does not differ from those recovered from nearby settlements, but the very limited range of forms seem to suggest a specific use. This opens up new prospects and generate questions relating to their use during ritual activities on the site (libations, offerings).

Mots clés : activités rituelles, âge du Fer, céramique, dépôt, La Tène finale, religion, sanctuaire.

Keywords: ritual activities, Iron Age, ceramics, hoards, Late la Tène, religion, sanctuary.

\section{LE SITE ET SON CADRE HISTORIQUE}

\section{Le contexte archéologique}

Le sanctuaire quimpérois de Parc-ar-Groas se situe au sommet du mont Frugy, un marqueur topographique fort à l'extrémité occidentale du plateau d'Ergué-Armel (fig. 1). Implanté au carrefour de voies antiques dont l'origine remonte vraisemblablement à la fin du premier âge du Fer ou aux débuts de l'époque gauloise, cet établissement s'intègre dans un paysage relativement dense d'habitats ruraux protohistoriques et antiques et surplombe à la fois la nécropole gallo-romaine de Creac'hMaria (à mi-pente) et l'agglomération secondaire antique de Locmaria (rives de l'Odet). Ce site a fait l'objet de nombreuses opérations archéologiques depuis la fin du XIX ${ }^{e}$ s. (fig. 2) : 1865 (Le Men, 1875), 1982 (Daniel, 1982), 1990 (Le Bihan, 1990a), 1995 (Le Bihan, 1995), 1996 (Le Bihan, 1996), 1998 (Le Bihan, 1998a et b), 2016 (Villard, 2016a et b) et 2017 (Nicolas et Villard, 2019). Ce n'est qu'à partir de la fouille de 1990 que le site fut interprété comme un lieu de culte à part entière. René-François Le Men le tenait pour un poste militaire (Le Men, 1875), et Louis Pape pour une villa dotée d'un fanum (Pape, 1978). En 2012, une publication fait la synthèse de ces découvertes (Le Bihan et Villard, 2012, chapitre 4). Les conclusions du rapport de la fouille de 2017 ajoutent quelques précisions complémentaires. 


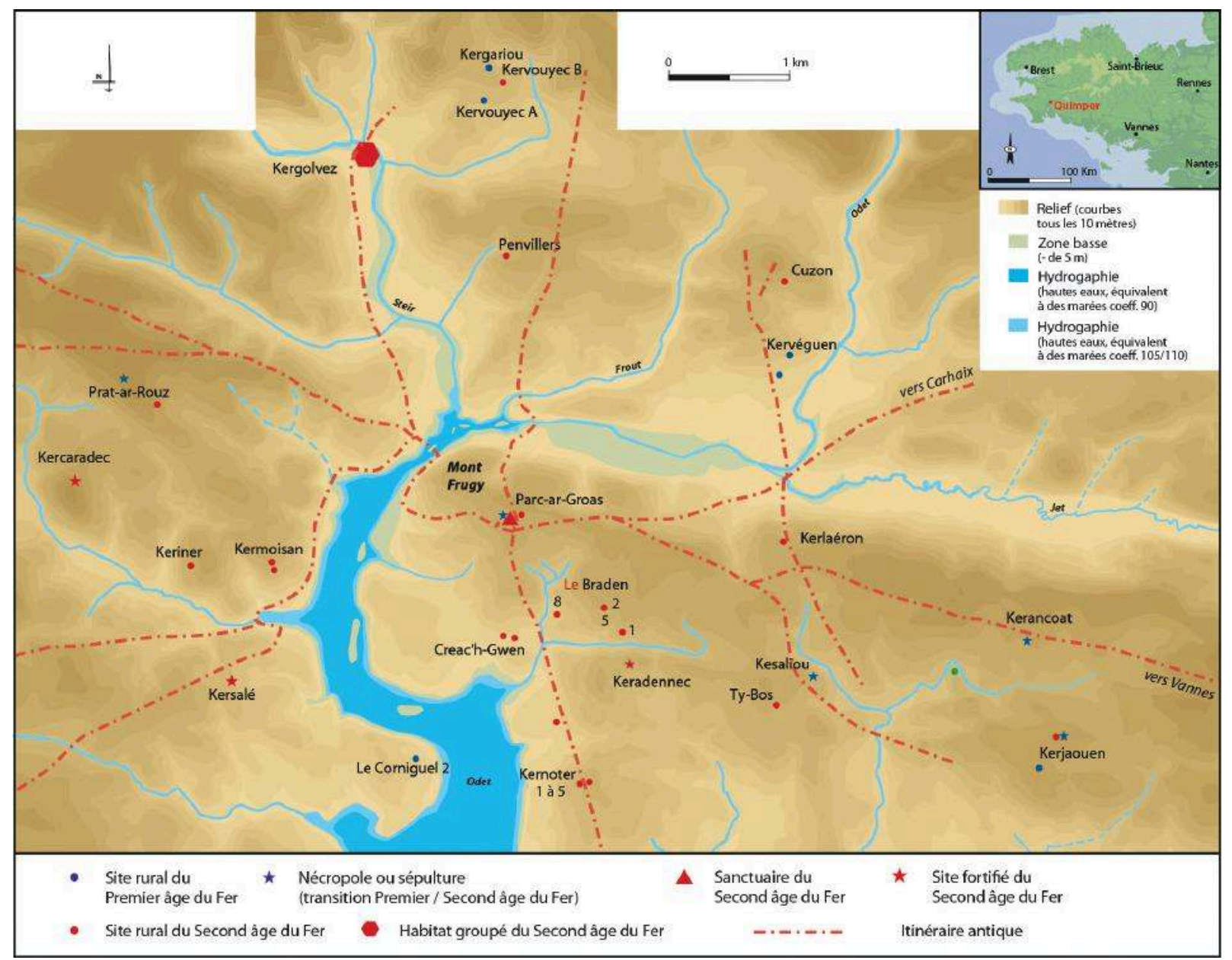

Figure 1: Le territoire de Quimper à l'âge du Fer.

Figure 1: The Quimper area during the Iron Age.

Toutefois, ces travaux s'attachent à l'Antiquité, période qui concentre la plupart des vestiges et leur évolution complexe. Les quelques éléments datés du second âge du Fer n'ont fait l'objet que de quelques mentions, sans étude approfondie, notamment l'abondant dépôt de poteries découvert en 1990. Afin de replacer cet ensemble dans l'histoire du sanctuaire, un résumé des principales phases d'occupation s'impose.

\section{L’histoire du sanctuaire}

L'histoire de l'établissement de Parc-ar-Groas couvre une longue période allant du $v^{e} s$. av. n. è. au haut Moyen Âge (fig. 3). Implanté sur une petite nécropole de la fin du premier âge du Fer, le sanctuaire de Parc-arGroas constitue l'un des lieux essentiels de l'organisation du territoire environnant à l'époque laténienne avec le hill-fort de Kercaradec et l'agglomération de Kergolvez (Le Goff, dir., 2014). Au cours de la période galloromaine, le complexe religieux du mont Frugy s'im- brique dans le paysage périurbain de Quimper antique (Le Bihan, 1984; Le Bihan et Villard, 2012). La notion d'acropole est retenue, induite par la topographie des lieux et le réseau routier préexistant : un itinéraire naturel et idéal conduit de la ville à la nécropole, puis aux temples.

\section{Laphase I}

La phase I regroupe les vestiges de l'âge du Fer organisés autour de deux thématiques : funéraire et religieuse.

La fonction funéraire est attestée par la présence de plusieurs urnes à crémation, mises au jour dans la partie occidentale du futur péribole antique ${ }^{1}$. En grande partie détruite par les aménagements ultérieurs, cette nécropole ne livre que trois sépultures encore en place et des fragments de vases dispersés. L'élément le plus ancien concerne une sépulture en coffre, délimitée par quatre dalles de

1. La limite du péribole antique, matérialisée par le mur d'enceinte de la phase V, sert de cadre de positionnement pour les phases anciennes I à III sur la fig. 3. 


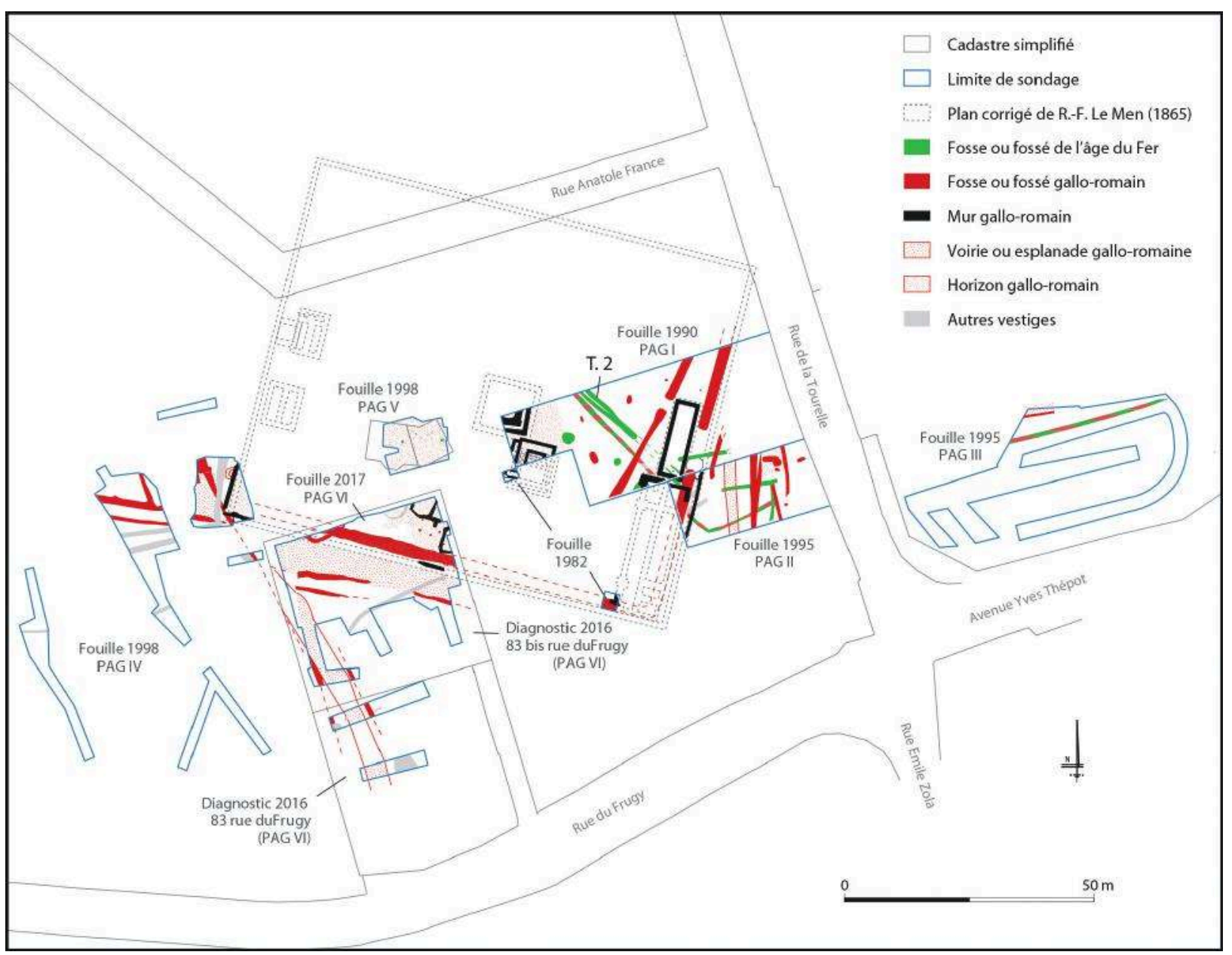

Figure 2 : Parc-ar-Groas : plan des vestiges découverts sur le sanctuaire lors des différentes interventions archéologiques (1865, 1990, 1995, 1998, 2016 et 2017).

Figure 2: Parc-ar-Groas: plan of the remains uncovered in the sanctuary during the various archaeological investigations.

chant, et recelant une urne à fond ombiliqué, haute encolure évasée et panse globuleuse ornée d'estampages et de grandes cupules à mamelons (Le Bihan, 1998a). Datée de la première moitié du v $v^{e}$. av. n. è., cette urne évoque celles des petites nécropoles du Hallstatt final et du début de La Tène ancienne, bien connues en Bretagne, et caractérisées à Quimper par celles de Kerancoat ou de Kerjaouen (Villard et al., 2006). À proximité, seul le fond ombiliqué d'une seconde urne, contenant encore quelques ossements brûlés, est signalé, entouré de fragments disséminés du vase. La troisième urne fut découverte au XIX ${ }^{e}$ s. par René-François Le Men. Il s'agit d'un très beau vase décrit par Pierre-Roland Giot (Giot, 1978; Giot et al., 1979, p. 316), associant décors peints et frises gravées. Datée de la fin de La Tène moyenne (début du $\mathrm{II}^{\mathrm{e}}$ s. av. n. è.), elle prolonge la fonction funéraire du site jusqu'à une date avancée du second âge du Fer. Cet aspect est conforté par la présence des fragments d'urnes (vase à piédestal, décors géométriques peints, décor de style libre) mis au jour lors de la fouille de 2017. Ces derniers se rattachent également à La Tène moyenne (entre le III ${ }^{\mathrm{e}}$ et le début du $\mathrm{II}^{\mathrm{e}} \mathrm{s}$. av. n. è.). Le petit cercle fossoyé, situé au cœur de la zone de découverte de ces urnes, semble associé à cet ensemble funéraire, tant par sa localisation que par sa stratigraphie. Faute de mobilier, il n'est pas possible de le rattacher à l'une des deux étapes de la nécropole (La Tène ancienne ou moyenne). En effet, la présence, dans le secteur, de quelques tessons erratiques susceptibles d'appartenir à l'âge du Bronze n'aide pas à la datation de ce petit fossé dont les caractéristiques rappellent celles de cercles funéraires. Enfin, la vocation funéraire du site est complétée par la présence d'un fragment de stèle, enfoui durant l'époque romaine au sein du sanctuaire (cf. infra, fig. 6).

La fonction religieuse se manifeste plus tard. Elle est représentée par différentes structures dont le tronçon de fossé (T. 2) contenant l'important dépôt de céramiques (fig. 4 haut). Il peut être mis en parallèle avec les fosses S. 7 et S. 9 et quelques trous de poteau. La seconde fosse contenait des restes osseux de bœufs en connexion, caractérisés par une sélection anatomique (thorax et cuisse d'au moins huit animaux, étude Patrice Méniel). Ce type 


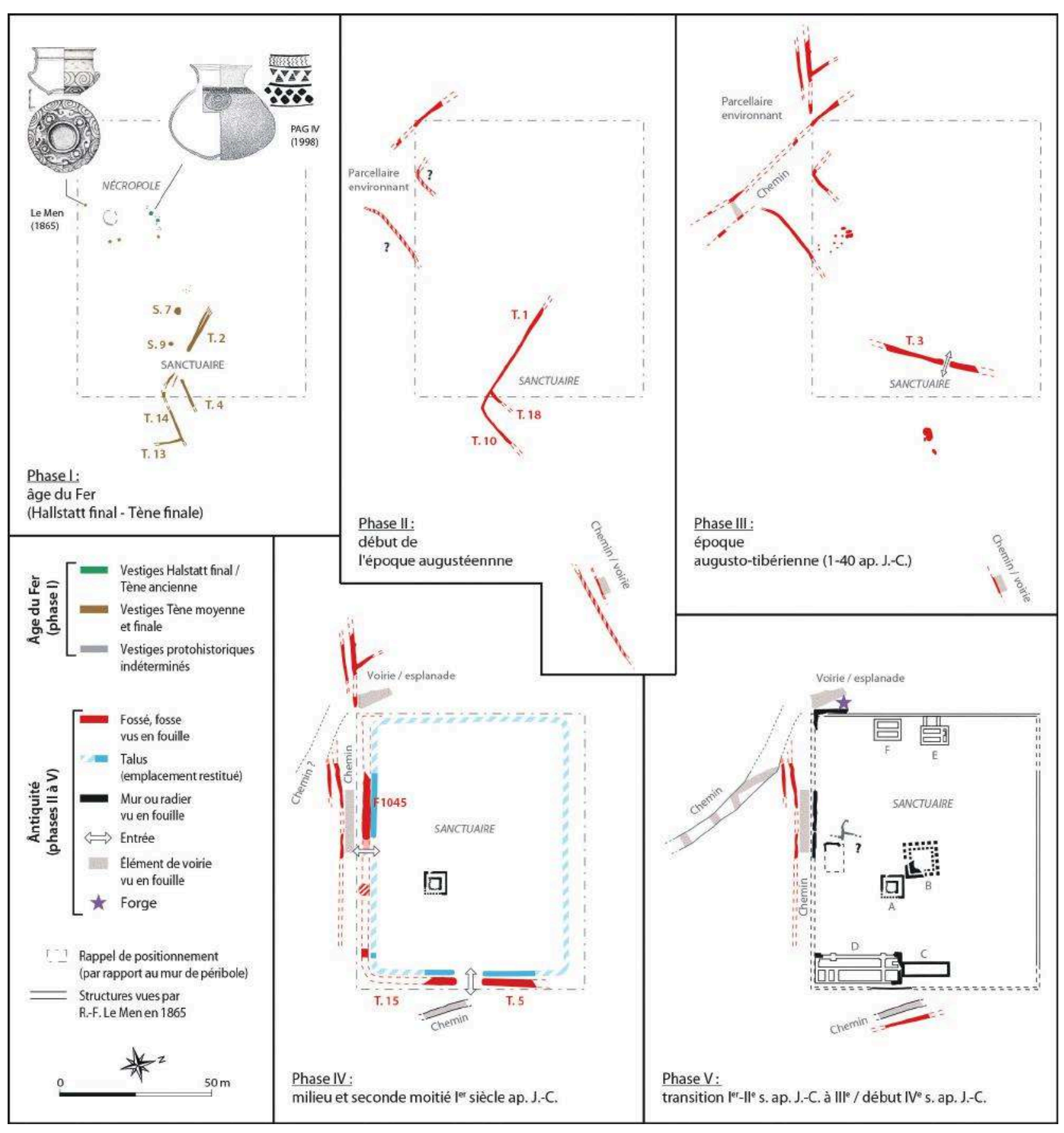

Figure 3 : Parc-ar-Groas, phases I à V, hypothèses d'évolution du sanctuaire et de son environnement.

Figure 3: Parc-ar-Groas, periods I to V, proposed phasing of the sanctuary and its surrounding.

d'offrandes animales, déposées dans des fosses, relève de pratiques rituelles fréquentes sur les sanctuaires de Gaule septentrionale (fig. 4 bas). Plusieurs tronçons de fossés (T. 4, T. 13 et T. 14) et la fosse S. 8, mis au jour en 1990 et 1995 , complètent le tracé de T. 2 .

Toutefois, il demeure difficile de retracer le plan et l'organisation de ce site gaulois à partir de ces vestiges lacunaires. La présence d'un souterrain des $\mathrm{IV}^{\mathrm{e}}$ ou distant de $250 \mathrm{~m}$, ne simplifie pas les choses. Longtemps inclus dans les pratiques religieuses du mont Frugy à la suite de sa confusion avec un important dépôt de statuettes en terre cuite enfoui dans un fossé gallo-romain attenant, un tel souterrain relève généralement des aménagements d'une exploitation civile, sans doute agricole. La relation avec les vestiges de l'âge du Fer antérieurs est également délicate à définir. Les éléments les plus anciens de ce secteur suggèrent la présence d'une simple nécropole 


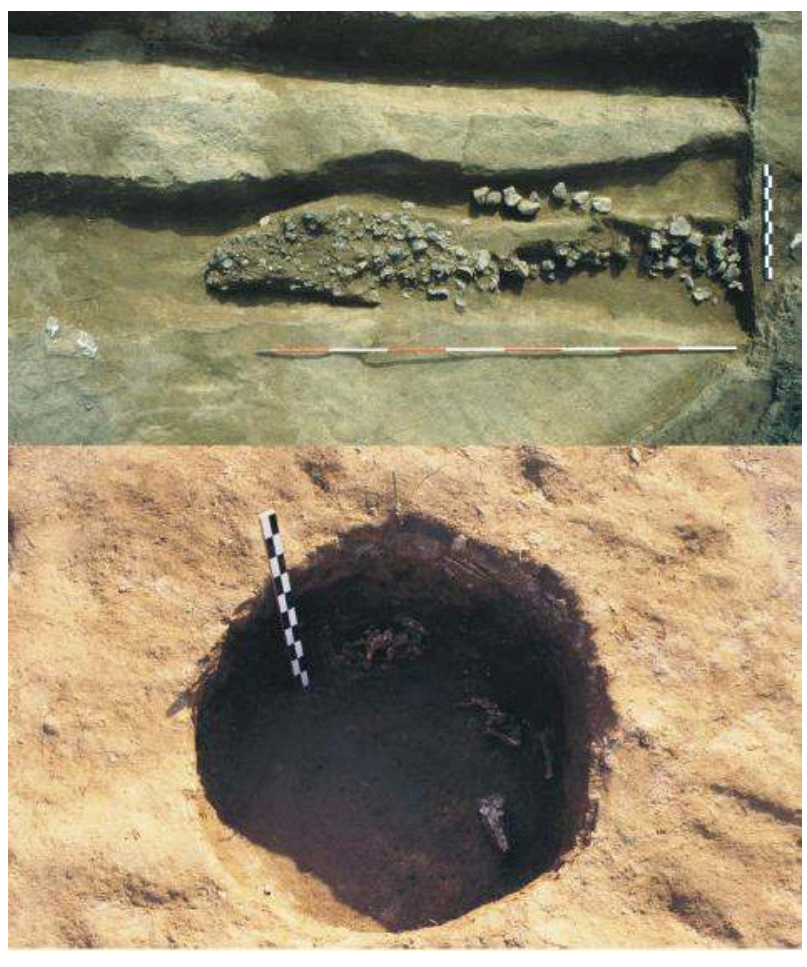

Figure 4 : Vue verticale du dépôt de poteries au sein du fossé T. 2 (en haut) et restes osseux de bœufs en connexion déposés dans la fosse S. 9 (en bas).

Figure 4: Vertical view of the pottery deposit in ditch $\mathrm{T}_{2}$ (top) and of articulated ox bones deposited in the pit S.9 (bottom).

mise en place dès le $v^{e} s$. av. n. è. sur ce secteur du mont Frugy sans doute occupé par un ou des sites d'habitat correspondants. Si le contexte funéraire se prolonge jusqu'au début du II ${ }^{\mathrm{e}}$ s. av. n. è., la date de création du sanctuaire demeure sujette à caution : Antiquité précoce ou bien dès l'âge du Fer.

Force est de reconnaître que, sans l'existence de la nécropole de l'âge du Fer plus ancienne, et de celle de nombreuses et indiscutables structures de temples galloromains immédiatement postérieurs au fossé gaulois T.2, l'interprétation des seuls vestiges laténiens de Parc-arGroas comme sanctuaire ferait débat. Sans l'importance du dépôt de poteries, une telle fonction de sanctuaire n'aurait même pas été envisagée. L'étude minutieuse de ce lot devient d'autant plus nécessaire (cf. infra).

Ce qui est certain, c'est que dès la fin de la protohistoire, les préoccupations d'ordre spirituel, tant religieuses que funéraires, tiennent une place importante dans ce secteur du mont Frugy. Cette dualité constitue un trait caractéristique que l'on observe de manière récurrente dans la formation d'un "paysage religieux " à l'âge du Fer et durant l'Antiquité. À Quimper, elle se traduira durant l'époque gallo-romaine (cf. infra) par le voisinage des sanctuaires du mont Frugy, dont celui de Parc-ar-Groas, et de la nécropole de Creac'h-Maria.

\section{La phase II}

À l'aube de l'Antiquité, le paysage de Parc-ar-Groas se modifie tout en conservant une certaine cohérence d'orientation des vestiges par rapport à la phase précédente. Les fossés T. 1, T. 10 et T. 18 (PAG I et II) succèdent aux aménagements laténiens. Malheureusement, ils sont fortement érodés par la topographie et les aménagements postérieurs. Ils ne livrent presque pas de mobilier. Seul leur recoupement par le fossé T. 3 (phase III), les place dans cette étape précoce. Aucun élément ne permet d'affirmer que ce nouvel enclos est doté d'une vocation religieuse. Cependant, intercalés, entre les fossés du sanctuaire gaulois, dont ils reprennent l'orientation, et celui de la première moitié du $\mathrm{I}^{\mathrm{er}} \mathrm{s}$. de $\mathrm{n}$. è., tout plaide en faveur d'une continuité de la fonction du site.

Plusieurs autres aménagements se mettent en place autour de cet établissement précoce. Vers l'ouest, un lambeau de sol gravillonné et des fossés bordiers évoquent les vestiges d'une voirie. L'orientation de ces fossés peut autant s'articuler sur celle des branches T. 4-T. 14 de l'établissement gaulois (phase I) que sur celle de T. 10-T. 18. Ces éléments, alignés sur près de $100 \mathrm{~m}$, suggèrent l'existence d'une voie ancienne, remontant probablement à l'âge du Fer, se dirigeant vers le sanctuaire. Cette voie estouest, courant sur le sommet du plateau d'Ergué-Armel, préfigure l'aboutissement de l'axe des voies antiques Quimper-Darioritum (Vannes) et Quimper-Vorgium (Carhaix). Vers l'ouest, des réseaux de parcellaires sont perçus en 1998 et 2017 (PAG IV et VI), près de l'angle sud-ouest du péribole antique.

\section{La phase III}

La phase III marque une première rupture par rapport à l'organisation et l'orientation des structures antérieures. Les aménagements périphériques occidentaux, quant à eux, perdurent et sont complétés par de nouveaux éléments : développement des éléments de parcellaire à l'ouest, trous de poteau et identification d'un cheminement nord-sud. Il n'est pas impossible que ces aménagements aient fonctionné dès la phase II, tout au moins en ce qui concerne les fossés et le chemin.

La principale innovation de la phase III réside dans la création d'un véritable péribole, délimité par le fossé T. 3 et ayant accueilli une palissade à poteaux jointifs. L’orientation de ce fossé diffère de 60 degrés par rapport aux aménagements précédents. Son tracé s'interrompt sur environ $2 \mathrm{~m}$, ménageant un point de passage, sans doute une entrée. La partie supérieure du comblement est scellée par une couche d'arène pure qui tend à effacer la structure du paysage après abandon ainsi qu'à sacraliser le mobilier enfoui, ce dernier étant probablement issu du 
déménagement d'infrastructures religieuses. À l'est de cet axe fossoyé, un ensemble de fosses et de profondes structures excavées a été repéré, associé à des foyers et à des couches charbonneuses concentrés sur une vingtaine de mètres carrés. Ces structures livrent un abondant mobilier céramique contemporain de celui du fossé T. 3 qui couvre toute la période augusto-tibérienne. L'abandon de ce sanctuaire de phase III intervient autour de $40 \mathrm{de} n$. è. Les aménagements fossoyés, à l'est de T. 3 , suggèrent que l'espace interne du sanctuaire se développait dans cette direction, les fosses et les concentrations de mobilier pouvant correspondre à des activités rituelles. L'absence de mobilier de cette période à l'ouest de T. 3, confirmerait cette hypothèse.

\section{La phase IV}

Suite au scellement du fossé T. 3 et de ces structures, un nouvel espace sacré quadrangulaire est délimité par un fossé (T. 5/T. 15/F1045). Un nouveau changement d'orientation est constaté. La façade orientale est décalée de 12,5 degrés par rapport à l'axe de T. 3. Cette orientation générale subsistera jusqu'à la fin de l'Antiquité. Elle sera reprise par les aménagements de la phase $V$, qui conserveront également les dimensions globales du péribole.

La façade orientale présente une interruption ménageant une entrée de $8 \mathrm{~m}$ de large. Le tracé du côté sud est mis au jour au fil de différentes fouilles. Il révèle la présence d'une seconde entrée. Cette façade méridionale est bordée d'un nouveau cheminement faisant le lien entre les vestiges de voirie à l'est et le cheminement à l'ouest. Plusieurs coupes stratigraphiques du fossé limitant le temenos révèlent une utilisation en structure ouverte bordée d'un talus. La phase IV est datée du milieu et de la seconde moitié du $\mathrm{I}^{\text {er }} \mathrm{s}$. de $\mathrm{n}$. è. Le fossé a fait l'objet d'un comblement rapide en fin d'occupation, associé à un dépôt massif de mobilier. Comme cela a été observé lors de la clôture de T. 3, il est probable qu'il s'agisse d'une manière d'enterrer, en le sacralisant, le mobilier présent dans l'enceinte et utilisé lors de cérémonies rituelles.

En ce qui concerne l'aménagement intérieur du temenos, on ne connaît que peu de choses, si ce n'est la présence d'un premier fanum maçonné. L'abondance de débris de tuiles, ainsi que de petits fragments d'enduits peints, tant dans les couches de comblement du fossé que dans les remblais, fruit des déconstructions et terrassements entre les phases IV et $V$, suggère que d'autres édifices ont existé dans cet espace. Ceux-ci ont pu être fondés sur solins et présenter des murs en bois et en terre, classique sur les sites ruraux, et parfois urbains, gallo-romains. Cependant, leur emplacement est inconnu. L'urbanisation actuelle n'offre plus d'opportunité de fouilles nouvelles.
Outre la création de nouveaux axes de circulation, la réorientation du péribole induit des bouleversements $\mathrm{du}$ paysage dans sa périphérie proche; on constate ainsi la disparition des aménagements " ruraux " de phases II/ III. C'est en effet à partir de cette période que d'autres temples sont érigés sur le sommet du mont Frugy, transformant cette colline en véritable acropole multipolaire (Le Bihan et Villard, 2012). Le nouveau chemin le long du côté méridional permet l'accès à l'intérieur du sanctuaire par la porte sud. Son tracé doit se poursuivre vers l'ouest où il reprend l'axe de la voirie repérée en 1895 (Dizot, 1896 et 1897), et se dirigeant vers l'agglomération antique de Quimper-Locmaria.

\section{La phase $V$}

La phase $\mathrm{V}$ voit une restructuration profonde des aménagements du sanctuaire à la charnière entre les $\mathrm{I}^{\mathrm{er}}$ et $\mathrm{II}^{\mathrm{e}} \mathrm{s}$., avec l'abandon des structures en bois et en terre au profit de constructions en pierres. Ces vestiges correspondent en grande partie à ceux connus depuis la fin du XIX $^{e} s$. par la fouille de René-François Le Men en 1865 (Le Men, 1875-1876).

La nouvelle enceinte est désormais matérialisée par un mur. Si les côtés nord et ouest ont été repérés dès 1865 , les deux autres n'ont été découverts que récemment. Un petit tronçon de $13,50 \mathrm{~m}$ de long a été mis au jour en 1995, accolé aux bâtiments C et D. Il corrige de manière significative le plan de Le Men qui plaçait, de manière hypothétique, la limite orientale beaucoup plus à l'est. Le flanc méridional n'est concrètement identifié qu'en 2016 : il s'agit d'un mur de 0,60 m de largeur monté à partir de petits moellons. La découverte, en 2017, d'un pan de mur abattu suggère une structure d'1,50 m de hauteur environ. Loin d'être spectaculaire, cette limite, essentiellement symbolique, sépare l'espace sacré de l'espace profane. Elle confirme les observations du XIX ${ }^{e}$ s. sur le côté occidental. Une telle hauteur pour ce mur ne doit pas être très éloignée de celle du talus de la phase précédente. L'espace enclos mesure $90 \mathrm{~m}$ sur $75 \mathrm{~m}$ $\left(6750 \mathrm{~m}^{2}\right)$, une surface interne légèrement supérieure à celle de la phase IV. Cette emprise est occupée par six constructions : deux temples ou fana au centre; deux petits bâtiments contre le mur occidental (lieu de manipulations rituelles, libations, présence de bassin, d'eau, de foyer); une grande construction, à plan de villa, plus massive dans l'angle sud-est (accueil des fidèles et/ou de logement des officiants?) et un bâtiment rectangulaire aux fondations plus modestes, implanté dans l'axe du précédent le long du mur est. La découverte de lambeaux de solins, en 2017, le long du mur méridional pourrait indiquer la présence d'un septième édifice. Par ailleurs, la contemporanéité de ces constructions n'est pas assurée. Si 
elles structurent l'intérieur du temenos durant la phase $\mathrm{V}$, leurs dates de construction ne peuvent être établies avec certitude, d'autant que cette phase dure plusieurs siècles jusqu'au $\mathrm{III}^{\mathrm{e}}$, voire le début du IV $\mathrm{I}^{\mathrm{e}}$ s., si l'on se fie aux monnaies découvertes par Le Men. Toutefois, au cours de cette période, aucun élément ne permet de définir le rythme des évolutions internes et des réaménagements potentiels. Ainsi, le point d'accès au sanctuaire de phase $\mathrm{V}$ demeure inconnu. Les ouvertures ménagées dans le fossé de phase IV sont obturées par le mur du péribole au sud et par les bâtiments à l'est. L'observation des murs ouest et nord sur une grande partie de leur tracé en 1865 limite les possibilités. Il est certain que la rigueur d'implantation des portes au milieu des façades est et sud est rompue au profit d'accès décentrés, mais non identifiés.

Autour de l'établissement, les aménagements périphériques et les espaces de circulation de phase IV persistent. L'esplanade externe occidentale accueille des vestiges d'une forge accolée au mur du péribole.

\section{La phase VI}

Contrairement aux étapes précédentes, la phase VI ne correspond pas à un réaménagement en profondeur des infrastructures. Il s'agit davantage d'hypothèses d'évolution de l'établissement durant l'Antiquité tardive. On ne sait rien de son abandon définitif. Les monnaies mentionnées par Le Men permettent de proposer une utilisation au moins jusqu' au IV ${ }^{e} s$., mais on ignore ce que deviennent ces infrastructures au-delà de cette date. L'état de conservation de certains murs sur 1,50 m d'élévation jusqu'au milieu du XIX ${ }^{e}$ s. démontre que les bâtiments n'ont pas été totalement détruits à la fin de l'Antiquité. Quelques éléments ont pu perdurer un temps, voire être réutilisés à d'autres fins. Une bague portant une croix « chrétienne " sur son chaton fut découverte dans l'enceinte du péribole, près du mur septentrional. Elle est datée de l'époque mérovingienne (Galliou, 1984). La mise au jour d'un sarcophage en pierre avec couvercle, orienté est-ouest, près du carrefour Saint-Laurent (aujourd'hui carrefour des rues de la Tourelle, du Frugy et de l'avenue Thépot) confererait au site de Parc-ar-Groas une ambiance chrétienne, entre le Bas Empire et le début du haut Moyen Âge (Dizot, 1896). Par ailleurs, l'étude des voies anciennes montre, qu'en dépit de l'abandon de l'agglomération gallo-romaine de Quimper-Locmaria à partir du Iv ${ }^{e}$ s., une partie d'entre elles demeure en fonctionnement sur le mont Frugy au haut Moyen Âge (Le Bihan et Villard, 2005), notamment la grande voie Quimper-Vannes. Enfin, certains textes et études hagiographiques (Tanguy, 1995) suggèrent qu'un site chrétien (premier évêché vers le $\mathrm{V}^{\mathrm{e}}-\mathrm{VI}^{\mathrm{e}} \mathrm{s}$.) a été implanté sur le sommet du Frugy, succédant au sanctuaire antique (Le Bihan et Villard, 2012, chapitre 4). S'il reste difficile d'étayer de telles hypothèses, les fouilles de la place Bérardier, près de l'église de Locmaria, montrent que, par la suite, l'évêché ne s'installe pas sur les rives de l'Odet avant le Ix ${ }^{e}$ s. (Le Bihan, dir., 2007). L'hypothèse de la reprise des infrastructures religieuses antiques de Parc-ar-Groas par les premiers évêques de Cornouaille a l'avantage de combler le hiatus historique entre le $\mathrm{VI}^{\mathrm{e}}$ et le $\mathrm{IX}^{\mathrm{e}}$ s. (Le Bihan et Villard, 2012), tout en assurant une christianisation de ces vestiges païens encore apparents dans le paysage.

\section{LE DÉPÔT DE VASES GAULOIS}

C'est dans ce long cadre historique que s'inscrit la découverte du dépôt de vases gaulois. Compte tenu de son remarquable état de conservation et du contexte particulier de sa découverte, cet ensemble, demeuré inédit, mérite une étude et une présentation approfondies.

\section{Le fossé T. 2}

Le réseau fossoyé T. 2, orienté nord-ouest/sud-est, constitue la structure principale des aménagements d'époque gauloise (cf. supra, phase I). Il a été repéré sur une quinzaine de mètres de longueur. Fortement arasé dans sa portion méridionale, il se prolonge toutefois sous la forme des segments T. 7 et T. 8, portant sa longueur à $30 \mathrm{~m}$ (fig. 5). La fouille de sa partie septentrionale, sur $9 \mathrm{~m}$, montre que la structure de T. 2 se dédouble : T. 2a à l'ouest et T. $2 \mathrm{~b}$ à l'est. Elle se prolonge dans cette direction au-delà des limites de la fouille. L'ensemble est comblé d'une terre arénitique brun clair incluant des traces et/ ou des poches de charbon de bois. Ces sédiments sont relativement homogènes entre les deux sous-ensembles. Toutefois, la présence de nombreuses pierres et de fragments de poteries dans T. $2 b$ et leur débordement audessus du bourrelet de substrat séparant les deux entités, montre que ce dernier est plus récent que T. 2a. La fouille fine de la branche septentrionale $\mathrm{T}$. $2 \mathrm{~b}$ révèle la présence du lot de poteries, concentré sur un segment de 5 mètres de longueur (fig. 6), complété par quelques éléments épars jusqu'au $8^{\mathrm{e}}$ mètre. Au-delà, l'érosion et les nombreux aménagements antiques ont fait leur œuvre. Tout porte à croire que cet ensemble de mobilier était plus important. N'a subsisté que la partie la plus profondément enfouie au sein du fossé. Vers le nord-ouest, la courte extension de la fouille du fossé, entre la limite de fouille perpendiculaire à l'axe de T. 1 et T. 2 (coupe 1) et la coupe stratigraphique 2 , montre une raréfaction des tessons. La limite du dépôt est-elle atteinte? L'urbanisation des parcelles voisines ne permettra probablement pas de répondre à cette interrogation. 


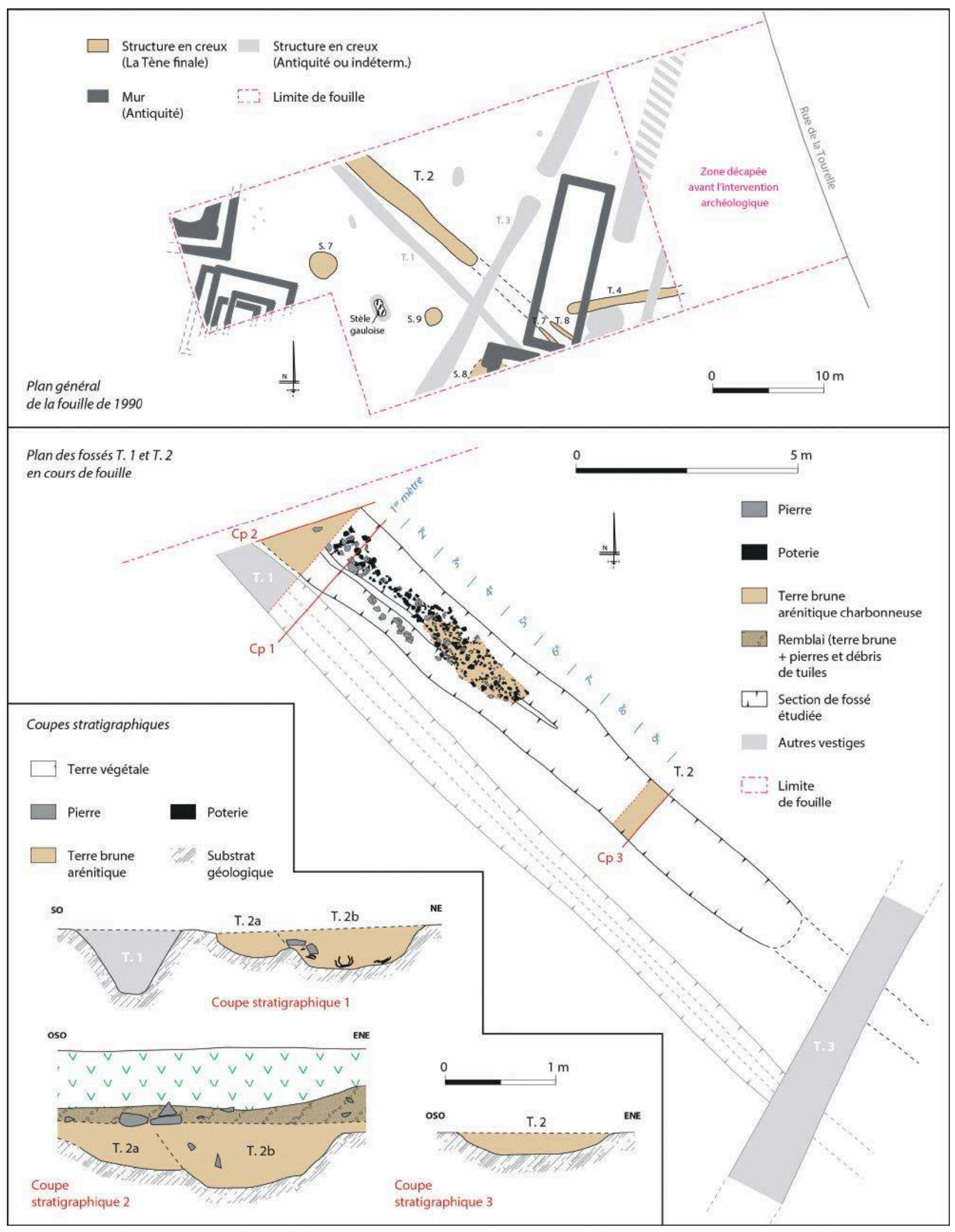

Figure 5 : Parc-ar-Groas : plan général de la fouille de 1990 ; plan de détail et coupes stratigraphiques du fossé T. 2.

Figure 5: Parc-ar-Groas: general plan of the 1990 excavation; detailed plan and sections of ditch T.2. 


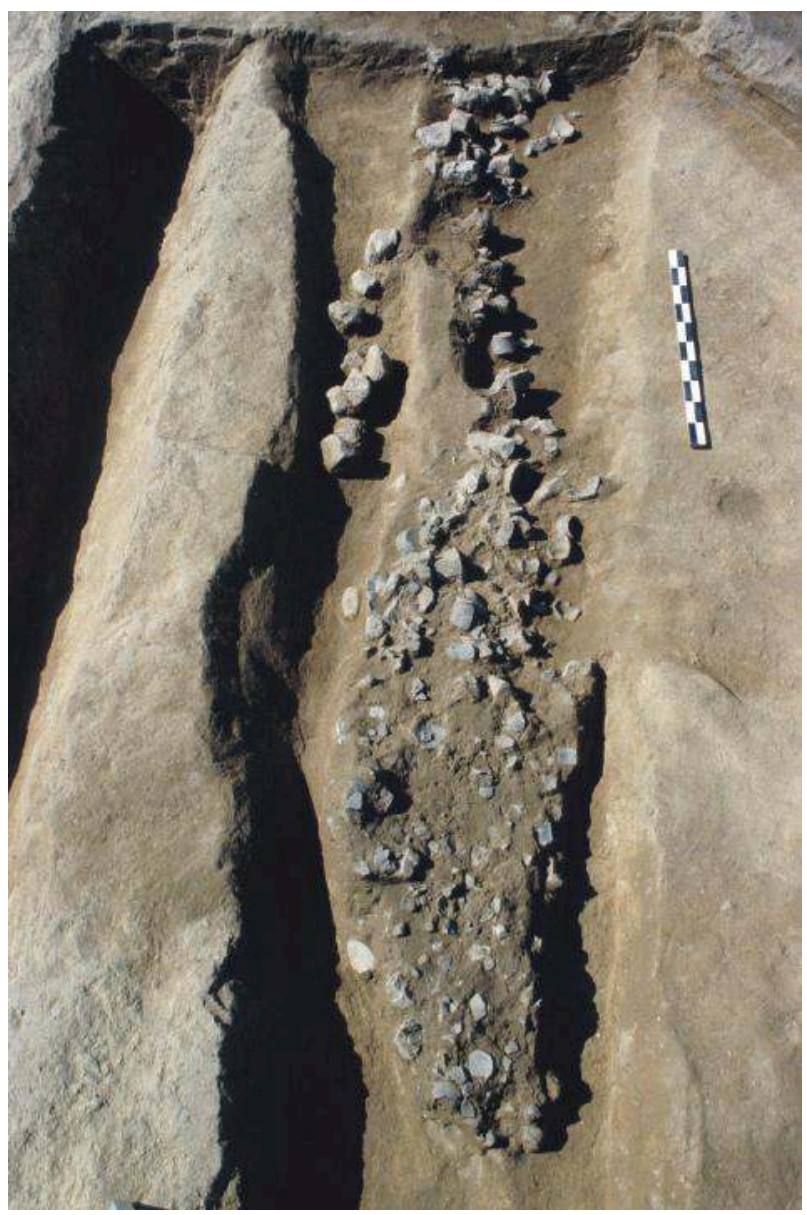

Figure 6 : Vue générale vers le nord-ouest du dépôt de poteries.

Figure 6: General view toward the north-west of the pottery deposit.

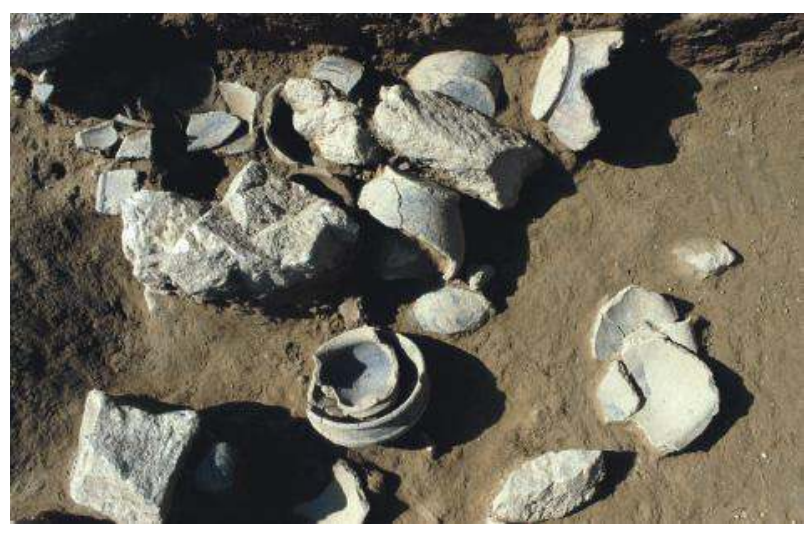

Figure 7 : Petit pot et jatte associés parmi les récipients du dépôt.

Figure 7: Small jars and bowls associated amongst the vessels in the deposit.

\section{Le lot de poteries}

Le lot de poteries mêle des vases entiers, parfois imbriqués les uns dans les autres (fig. 7), et des récipients plus dispersés ou incomplets. Certains sont brisés, écrasés par les pierres entremêlées parmi les vases. D'autres ont été

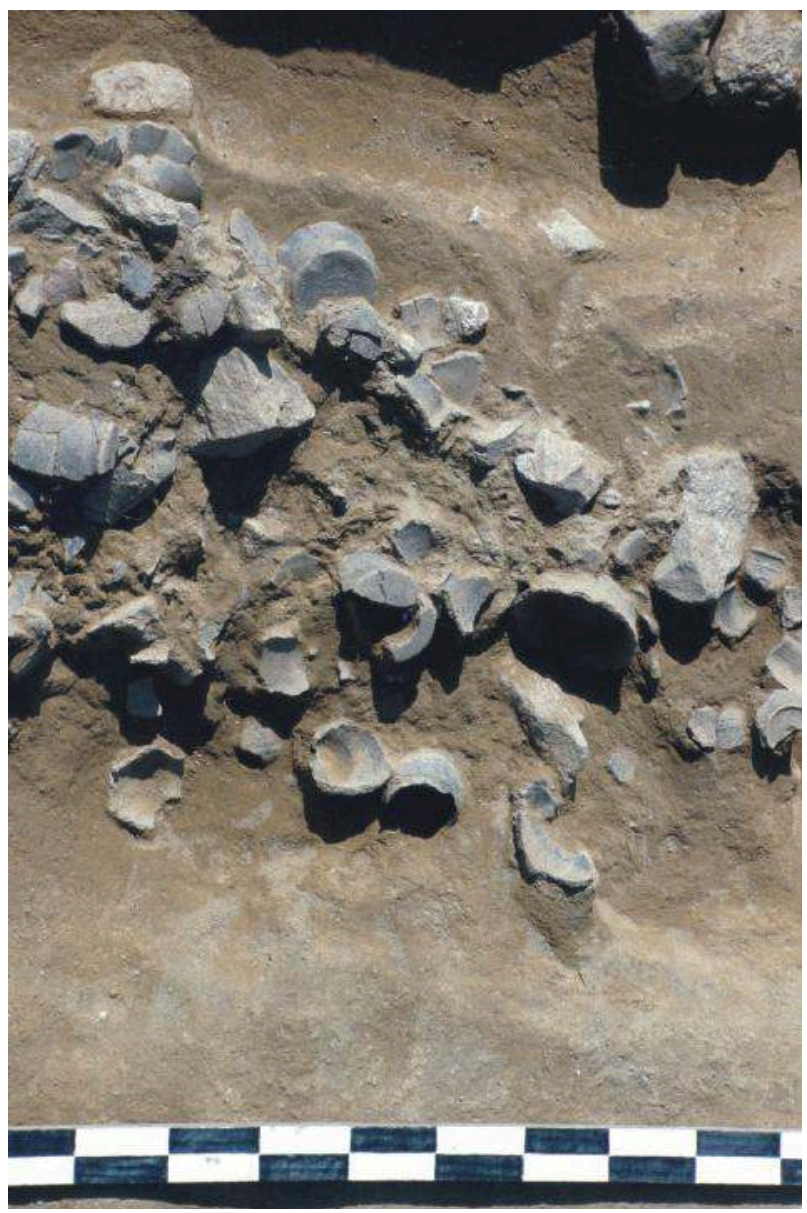

Figure 8: Concentrations de vases imbriqués au sein du dépôt.

Figure 8: Concentration of nested pots within the deposit.

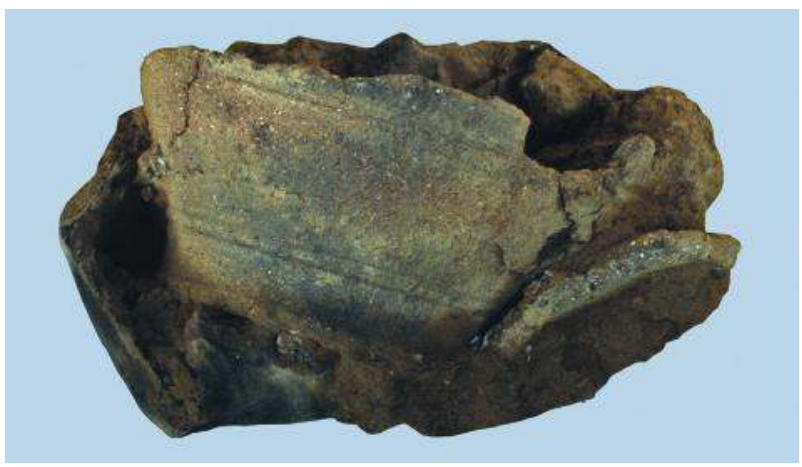

Figure 9 : Bloc de sédiment contenant un vase prélevé sur le terrain pour étude en laboratoire.

Figure g: Sample of soil containing a pot taken from the site for laboratory analysis.

tronqués par les événements ultérieurs ayant affecté le site. Là où les regroupements de vases sont moins denses, ces derniers peuvent être prélevés individuellement. En contrepartie, les concentrations plus compactes (fig. 8) nécessitèrent occasionnellement des prélèvements en blocs dont la fouille se fit ensuite dans le laboratoire du Centre 
de recherche archéologique du Finistère (fig. 9). Dès la phase de terrain, il apparut que le répertoire des formes se limite à des jattes, des gobelets et surtout des petits pots, mis au jour en nombre élevé.

\section{3. ÉTUDE TYPOLOGIQUE}

\section{Généralités}

Une fois le remontage des vases effectué, 214 dessins de récipients purent être réalisés dont seuls 30 présentent un profil quasi complet (fig. 10). Sur 25 autres, au moins $75 \%$ du profil est conservé (encolure et lèvre ou fond manquant). Il n'est par ailleurs pas possible de raccorder avec certitude la plupart des parties supérieures aux nombreux fonds répertoriés. Si l'on se base uniquement sur ces fonds, un NMI de 138 vases est atteint. En intégrant quelques critères complémentaires à l'ensemble du lot, tels que les types de productions, les diamètres de rebords par rapport à ceux des fonds pour certains profils incomplets..., un nombre supérieur à 150 vases peut être envisagé pour ce dépôt. L'état de conservation est relativement bon si l'on considère que, même pour les récipients au profil réduit, une grande partie du pourtour, voire la totalité de celui-ci, est conservée (fig. 7). La plupart des cassures sont nettes, indiquant que les vases ont été brisés au moment du dépôt, ou peu avant, ou par compactage des sédiments au fil du temps. La disparition d'une partie des vases souligne également que ce lot n'est qu'une partie d'un ensemble plus important aujourd'hui tronqué.

\section{Les aspects technologiques des poteries}

À l'image de la plupart des poteries mises au jour sur les sites d'habitat voisins d'époque gauloise, le lot de Parc-arGroas se divise selon deux catégories de productions : des vases à pâte commune micacée et des vases réalisés en pâte proto-onctueuse. Le premier type se caractérise par des récipients de couleur brun-gris à noir, dont la pâte est plus ou moins dégraissée par des grains de quartz et de feldspath. Le second type est représenté par des vases bruns, brun-roux, mais aussi brun-gris, dont la surface est un tant soit peu soyeuse au toucher. Toutefois, les concentrations de dégraissant, notamment de quartz et de mica, dans la composition de certains pots rend parfois délicate la distinction entre les deux productions. De telles variations d'inclusions dans les pâtes proto-onctueuses ont également été observées sur la céramique de la ferme laténienne du Braden I avec des exemplaires aux compositions très hétérogènes (Faulon, 1994). À Parc-ar-Groas, sur la base du nombre de dessins réalisés, la proportion de poteries communes micacées est d'environ $65 \%$ des récipients pour $35 \%$ de poteries proto-onctueuses.
Figure 10 : Clichés de petits pots et de jatte à cordon issus du dépôt.

Figure 10: Pictures of small jars and cordoned bowls from the deposit.

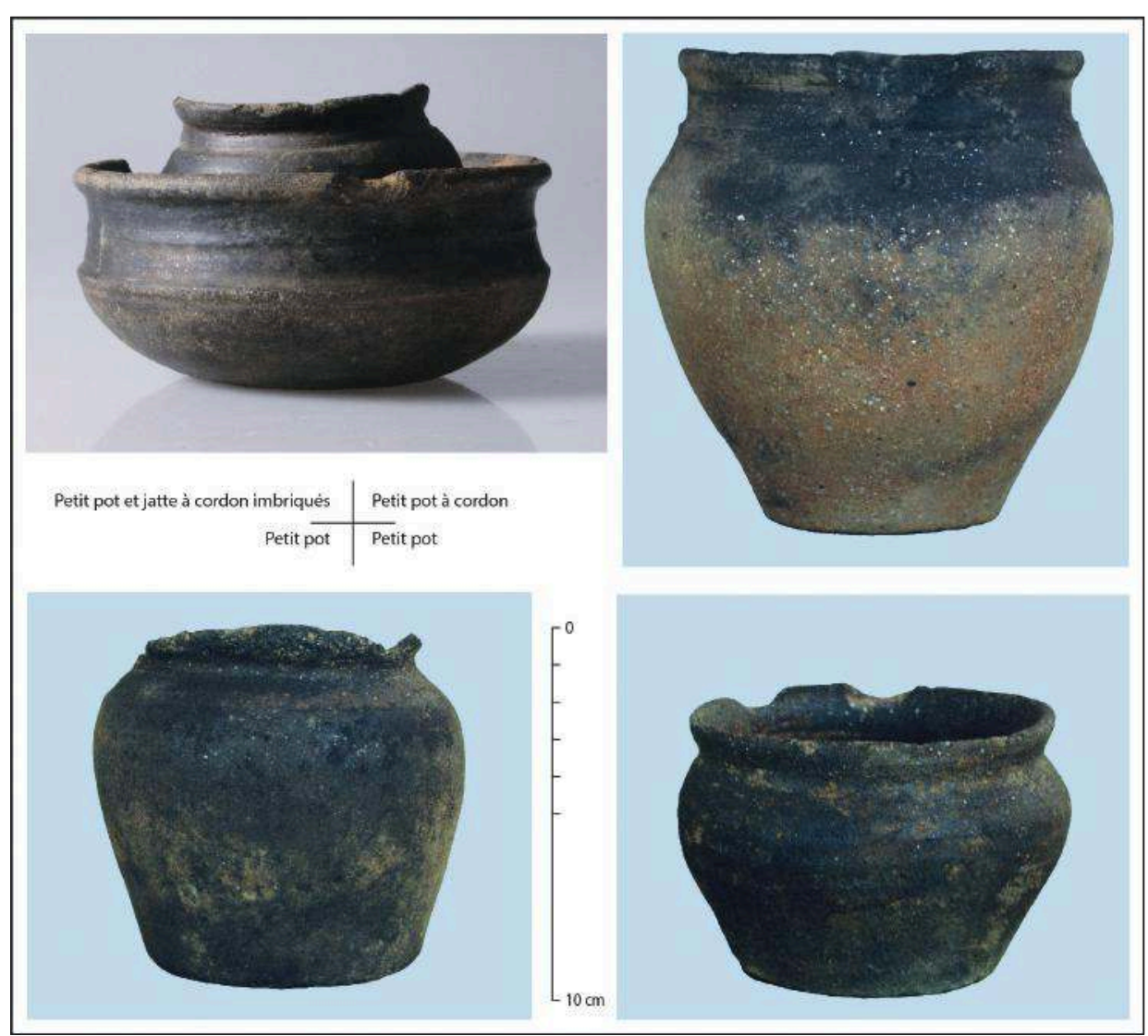


En ce qui concerne les techniques de fabrication, l'ensemble des vases est monté au tour, ou tout au moins fait l'objet d'une étape d'élaboration à la tournette. La présence de quelques stries, ainsi que les modes de décors (cf. infra) l'attestent. Toutefois, ces traces ont été en grande partie effacées par la finition générale des récipients, basée sur un lissage. Par ailleurs, le lustrage de certaines parties des vases comme les encolures et les rebords extérieurs, quelquefois la base de la panse, donnent leur aspect final à ces productions, quel que soit le type de pâte. Dans deux cas, on note également la présence d'une enduction au graphite.

Le registre des décors est réduit. Il se limite à des cannelures, de fins cordons ou des moulures. Ces ornementations en registres horizontaux réguliers, facilitées par le montage au tour, sont caractéristiques de La Tène moyenne-finale dans la région. Typologiquement, elles appartiennent aux décors de type $\mathrm{M}$, pour les cordons, et $\mathrm{N}$, pour les cannelures, de la classification bretonne (Cherel et al., 2018); plus particulièrement aux décors M2 (cordon simple ornant le col ou l'épaulement), M4 (une ou plusieurs baguettes espacées encadrée de cannelures), N1/2 (cannelure simple ou double sur l'épaulement) et N5 (plusieurs registres de cannelures serrées espacées sur la hauteur de la panse). Pour la plupart, ces décors sont datés, en Bretagne, entre le dernier quart du $\mathrm{III}^{\mathrm{e}}$ et le $\mathrm{I}^{\mathrm{er}}$ s. av. n. è., excepté M4 un peu plus récent (deux derniers siècles av. n. è.).
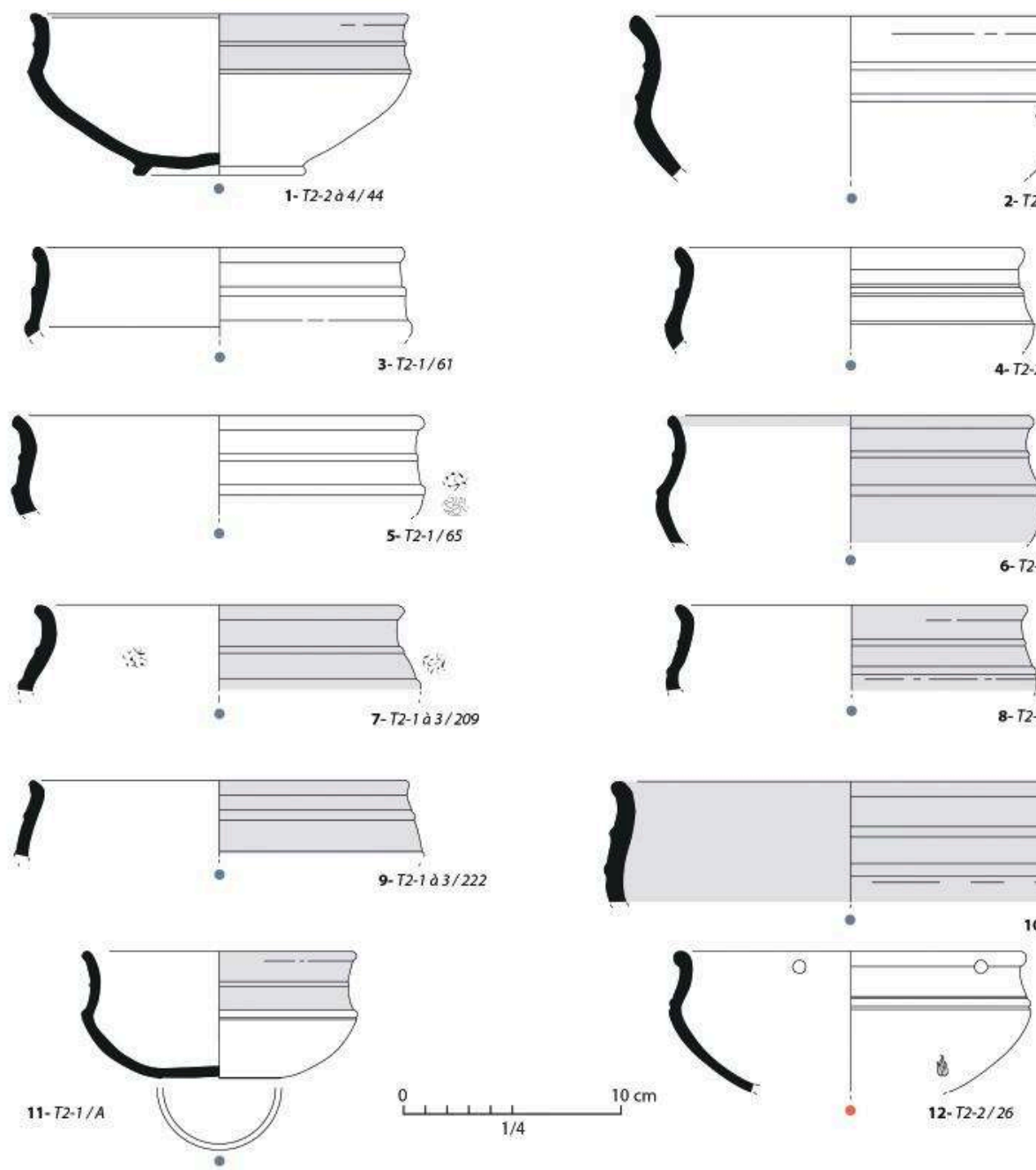

- Poterie commune

- Poterie proto-onctueuse

Traces de suie

और Usure, surface abìmée
Surface lissée
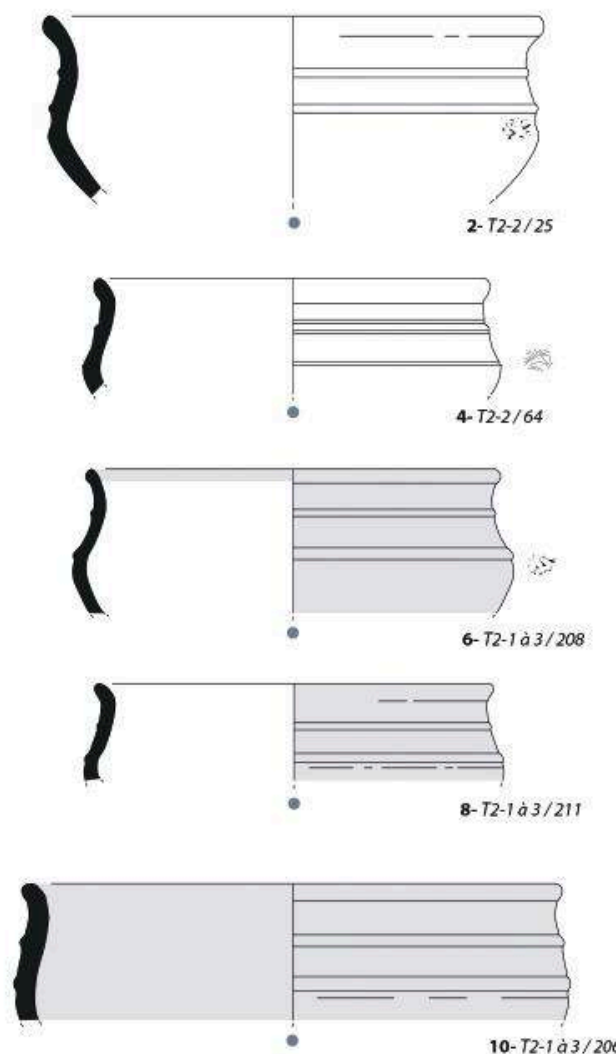

$10-T 2-1 \dot{a} 3 / 206$

- Traces de coup de feu

Figure 11 : Parc-ar-Groas : les jattes à simple cordon sur l'encolure.

Figure 11: Parc-ar-Groas: the bowls with single cordon at the base of the neck. 


\section{Le classement typologique}

\section{Les jattes}

Les jattes mises au jour à Parc-ar-Groas sont relativement peu nombreuses : on compte vingt-huit exemplaires attestés, ainsi que deux fonds isolés. Elles se déclinent selon quatre modèles.

Les plus nombreuses sont les jattes à épaulement marqué galbé, avec une douzaine d'exemplaires (fig. 11). L'encolure concave, légèrement rentrante, s'orne d'un unique cordon médian. Cette partie supérieure est fréquemment soigneusement lissée ou lustrée. Un cordon complémentaire peut souligner l'épaulement, marquant la limite inférieure de la zone lustrée. Sur les exemplaires complets, le fond repose sur un petit pied annulaire, parfois réduit à sa plus simple expression (micro-bourrelet sous le fond). Le rapport hauteur/largeur moyen est de
0,4 . Seul un exemplaire est produit en pâte proto-onctueuse. Il a la particularité d'être percé de deux trous (Ø $6 \mathrm{~mm}$ ), distants de $8 \mathrm{~cm}$ sous la lèvre. Ces jattes à simple cordon sont bien connues à Quimper sur les sites du Braden I (Faulon, 1994, planches 8 à 11), du Braden II (Le Bihan et al., 1987, planche I), de Keradennec (Le Bihan, 1990b), de Kergolvez (Le Goff, dir., 2014, fig. 642), de Kervouyec II (Nicolas, 2013, p. 138) ou des Hauts-de-Penvillers (Le Bihan, 1997, fig. 45). Elles s'associent au type 31 breton (Cherel et al., 2018, fig. 8 et p. 278) daté entre 75 et 50 av. n. è. Ce modèle évoluera par la suite au début de l'époque romaine, sous différentes formes, jusqu'au deuxième quart du $\mathrm{I}^{\mathrm{er}} \mathrm{s}$. de n. è. (Villard, 2012a et b).

La deuxième catégorie regroupe les jattes typologiquement proches du modèle précédent, mais plus profondes, avec un rapport hauteur/largeur de 0,55 (fig. 12). Elles s'en distinguent par leur ornementation moulurée plus
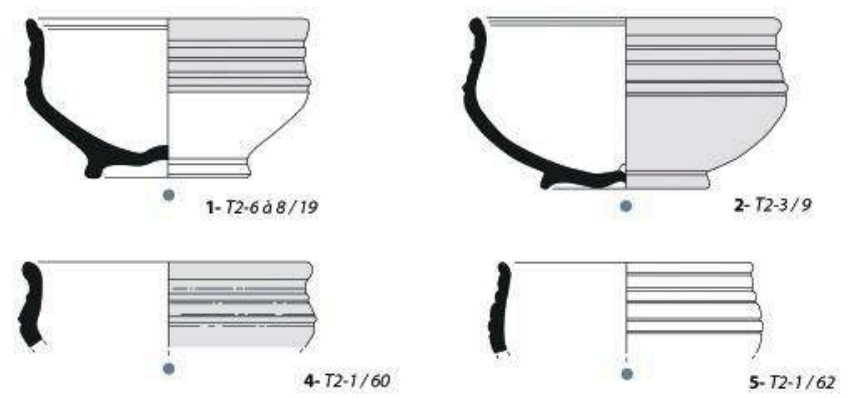

5- $72-1 / 62$
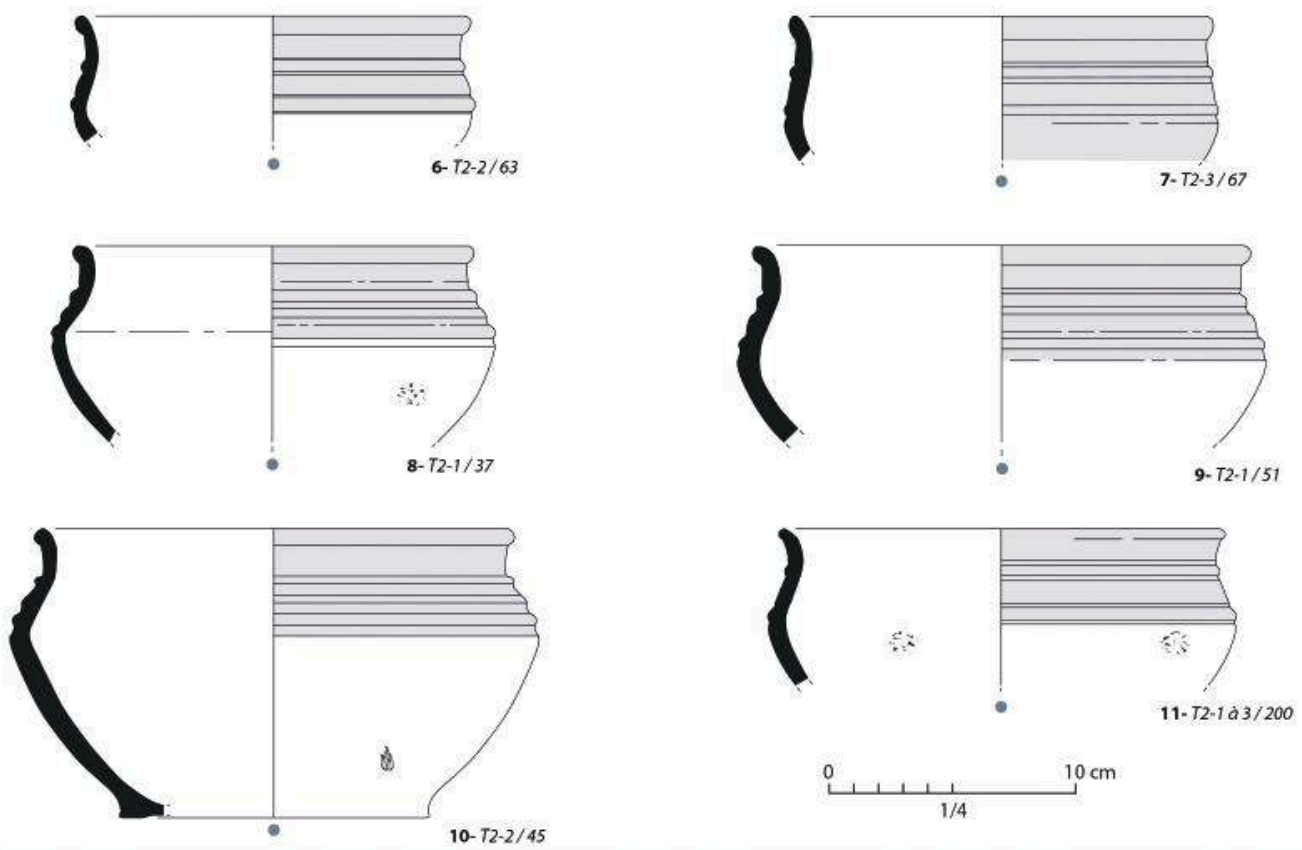

Figure 12 : Parc-ar-Groas : les jattes moulurées à cordons multiples.

Figure 12: Parc-ar-Groas: the grooved-cordon bow/s with multiple cordons. 
complexe de type M4 (superposition de plusieurs cordons encadrés de deux cannelures) couvrant la partie supérieure subverticale à rentrante, entre l'épaulement et le rebord. L'épaule galbée est également plus arrondie. Le fond présente un pied annulaire plus ou moins marqué. Cette forme se décline en deux modules : quatre récipients de petite taille $(\varnothing$ maximum de $12 \mathrm{~cm}$ ) et cinq de plus grandes dimensions ( $\varnothing$ maximum de $22 \mathrm{~cm}$ ) respectant les mêmes proportions. Toutes ces jattes sont réalisées en pâte commune micacée. Presque tous les exemplaires ont leur partie supérieure externe soigneusement lissée à lustrée, ce traitement pouvant s'étaler sur toute la hauteur du vase, comme le montre l'un des petits vases. D'une manière générale, ces jattes s'apparentent au type $40 \mathrm{a} / \mathrm{b}$ breton (Cherel et al., 2018, fig. 9 et p. 281) daté entre 75 av. n. è. et le changement d'ère. Ce modèle se retrouve à Quimper sur les habitats du Braden I (Faulon, 1994, planches 9 et 10), de Penvillers (Le Bihan, 1997, fig. 25), ainsi que dans l'agglomération de Kergolvez. Elles sont également présentes à Pluguffan "Ti Lipig » (Le Gall et Paranthoën, 2020, fig. 346). Dans le détail, la petite jatte $n^{\circ} 1$ (fig. 12-1), avec son encolure plus verticale, se rapproche d'un petit vase de Kergolvez (Le Goff, dir., 2014, fig. 855) rattaché au type $35 \mathrm{~b}$ breton. Ce type est contemporain du précédent avec toutefois une apparition plus précoce, dès $175 \mathrm{av}$.

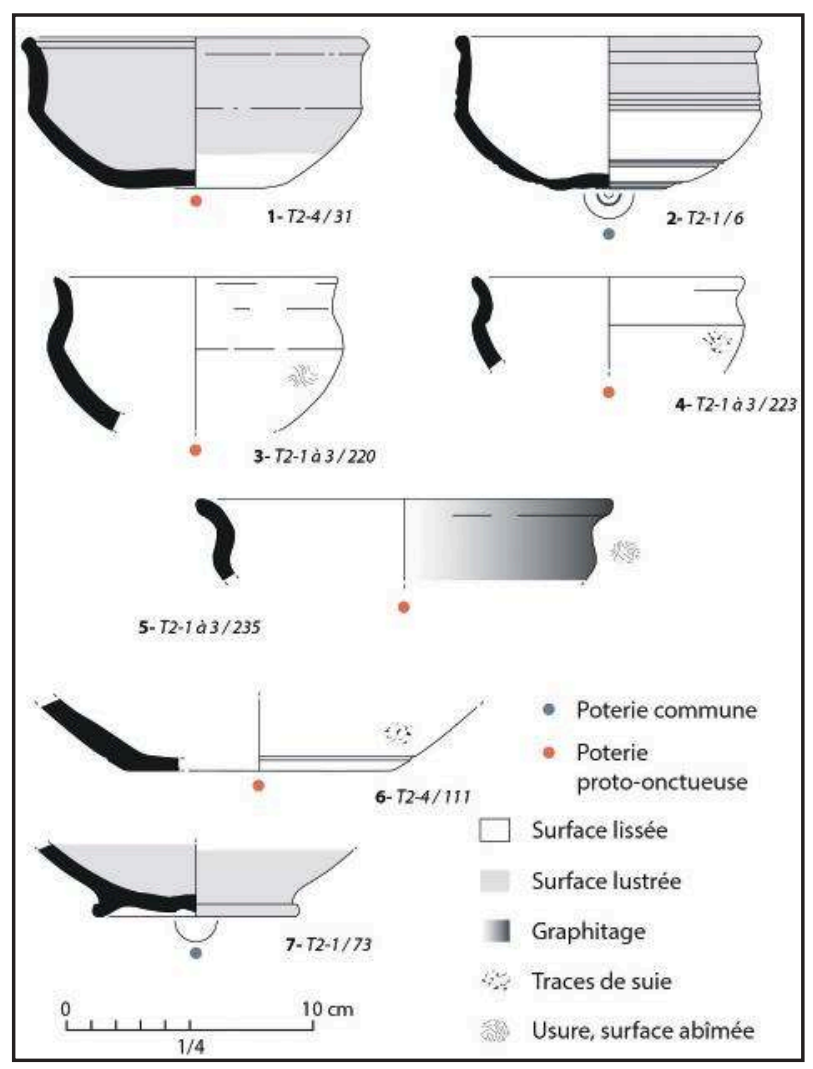

Figure 13 : Parc-ar-Groas : les autres jattes.

Figure 13: Parc-ar-Groas: the other bowls. n. è. Pour le Grand Ouest, certaines affinités s'observent également avec le type 37b des Pays de la Loire (Cornec et al., 2018, fig. 30) de la première moitié du $\mathrm{I}^{\mathrm{er}}$ s. av. n. è. Là encore, ces formes perdureront sous d'autres modes de production au cours de l'Antiquité précoce.

Le troisième modèle de jatte possède un col vertical à lèvre éversée. Deux exemplaires sont recensés, l'un dénué d'ornementation et en pâte proto-onctueuse, l'autre en pâte commune orné d'une moulure sur l'épaulement et de deux fines cannelures serrées en bas de panse (fig. 13-1 et 2). Le fond plat est légèrement bombé. La première jatte est presque intégralement lustrée (intérieur et extérieur), tandis que, sur la seconde, seule la partie supérieure externe l'est. Ces jattes s'intègrent à la forme de type 35a breton (Cherel et al., 2018, fig. 9 et p. 279) en usage au cours de La Tène finale (II ${ }^{\mathrm{e}}$ s. av. n. è. au changement d'ère). Localement, ces formes sont fréquentes au Braden I (Faulon, 1994, planche 6), au Braden II (Le Bihan et al., 1987, planche II), à Kergolvez (Le Goff, dir., 2014, fig. 679) ou aux Hauts-de-Penvillers (Le Bihan, 1997, fig. 16, 25 et 39), ainsi qu’à Pluguffan "Ti Lipig " (Le Gall et Paranthoën, 2020, fig. 346).

Le quatrième modèle est représenté par une jatte à profil en esse évasé en proto-onctueuse dont la surface externe est graphitée (fig. 13-5). Bien qu'incomplète, son profil la classe dans des formes relativement basses, proches du type 28 breton (Cherel et al., 2018, fig. 8 et p. 278) également daté entre le $\mathrm{II}^{\mathrm{e}}$ s. av. n. è. et le changement d'ère. Ce modèle est présent sur la plupart des habitats quimpérois précités.

Deux petites formes ouvertes à profil en esse, relativement profondes, complètent cet ensemble (fig. 13-3 et 4), ainsi que deux fonds au bas de panse très évasé, l'un plat, l'autre à pied annulaire (fig. 13-6 et 7).

\section{Les gobelets}

Les gobelets sont représentés par quatre modèles différents, et figurés par huit vases.

Le premier modèle possède un profil en esse très peu marqué, une large ouverture et un faible resserrement à l'encolure. Le fond, à bourrelet débordant, est assez étroit, conférant un aspect élancé au profil (fig. 14-1 à 5). Ces exemplaires sont ornés de registres de moulures et de cannelures (type M4) espacés entre la base du col et le bas de panse. Le diamètre maximal peut être assez bas, presque médian. Le rapport hauteur/largeur est compris entre 0,8 et 0,95 . Ces gobelets sont difficilement classables. $\mathrm{La}$ comparaison la plus proche correspondrait au type $48 \mathrm{c}$ (Cherel et al., 2018, fig. 10 et p. 283) par ses proportions et ses dimensions. Il s'agit là davantage d'affinités que de ressemblances affirmées. Ce type est en usage entre 150 et $125 \mathrm{av}$. n. è. Toutefois, à la différence de ce modèle, les 
exemplaires de Parc-ar-Groas ont systématiquement une courte lèvre éversée et sont toujours ornés de moulures de type M4. Par ces caractéristiques, ils forment également un ensemble cohérent avec l'une des catégories de petits pots (cf. infra, 3.3.3.). Ils pourraient se rapprocher des variantes de petites dimensions des pots de type H3-12/4 de l'agglomération de Kergolvez (Le Goff, dir., 2014, fig. 855). Le vase fig. 19-3 trouve un équivalent par sa taille et sa morphologie dans une fosse de ce même site (Le Goff, dir., 2014, fig. 462).

Le deuxième type est plus ouvert, sans resserrement entre le haut de panse et la lèvre en simple bourrelet. Un fin cordon encadré de cannelures orne son diamètre maximal (fig. 14-6). Seule la partie supérieure est conservée. Là encore, les références s'orientent vers les gobelets « tronconiques » de type 48b/c bretons, à l'image d'un gobelet issu d'Hennebont « Polvern » (Daire, 1992, planche XVIII-2). Des exemplaires similaires sont recensés à Quimper au Braden I (Faulon, 1994, planches 13 et 14), à Locquirec "Moulin de la Rive " (Daire, 1992, planche XVIII-2) ou Paule "Camp de Saint-Symphorien " (Menez, 2008,
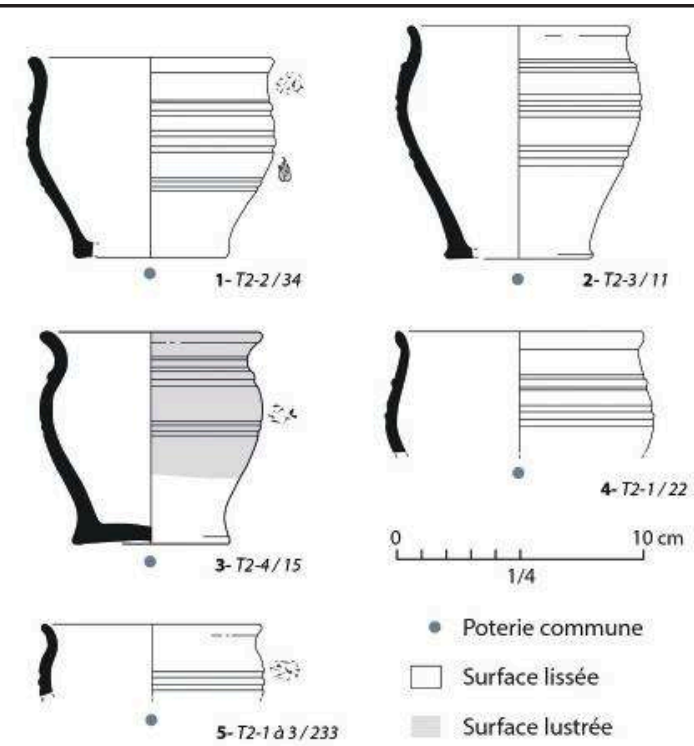

- Poterie commune

Surface lissée

Surface lustrée

E: Traces de suie

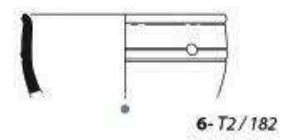

i Traces de coup de feu
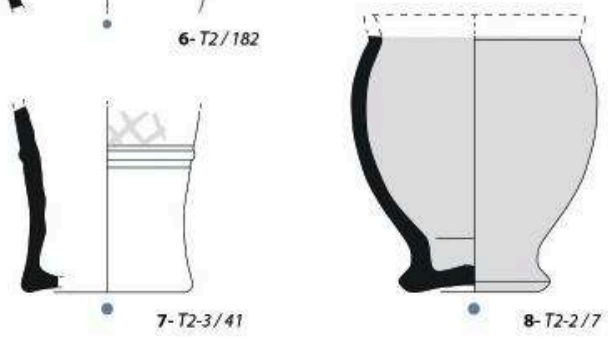

Figure 14 : Parc-ar-Groas : les gobelets.

Figure 14: Parc-ar-Groas: the beakers. fig. 224) pour ne citer que ces quelques exemples de Bretagne occidentale.

Le troisième correspond à un récipient balustre à base rétrécie, étroit fond soulevé, et panse convexe régulière (fig. 14-8). La lèvre manque. Les surfaces internes et externes sont intégralement lustrées. Ce vase, au rapport hauteur/largeur estimé à 0,9 , trouve un équivalent quimpérois sur l'habitat des Hauts-de-Penvillers (Le Bihan, 1997, fig. 13). De plus grande taille, ce dernier définit à lui seul le type 81 breton (Cherel et al., 2018, fig. 18 et p. 296), daté des trois premiers quarts du II ${ }^{\mathrm{e}} \mathrm{s}$. av. n. è. Le vase de Parc-ar-Groas s'apparente également au type 48c (cf. supra) par sa petite taille.

Le quatrième modèle n'est connu que par sa partie inférieure caractérisée par un étroit fond légèrement soulevé, et par une panse tronconique légèrement concave à la base (fig. 14-7). La panse s'orne d'une moulure (cordon encadré de cannelures) surmontée d'un décor de croix lustrées. Là encore, la famille du type 48 breton peut être évoquée. Cette forme étroite et élancée présente également certaines affinités avec un gobelet orné de trois cordons similaires, issu de l'horizon 3 (fin $\mathrm{II}^{\mathrm{e}}$-milieu du $\mathrm{I}^{\text {er }}$ s. av. n. è.) de l'agglomération de Quimper Kergolvez (Le Goff, dir., 2014, fig. 861). Le décor lustré rejoindrait le type L5 du corpus breton (Cherel et al., 2018, fig. 27 et p. 309-311) en usage entre le II $^{\mathrm{e}}$ et la seconde moitié du $\mathrm{I}^{\mathrm{er}}$ s. av. n. è.

\section{Les petits pots}

Les petits pots constituent la forme majoritaire au sein du dépôt avec quatre-vingt-un exemplaires recensés. Trapus, ils se distinguent des gobelets précédents par une encolure plus resserrée, un profil ovoïde à épaulement haut et une lèvre plus nettement éversée. Sur les exemplaires décorés, la partie supérieure de la panse, juste sous la lèvre, forme une bande tronconique lisse plus ou moins large avant les premières moulures ou cannelures. Quatre-vingt-six exemplaires sont recensés avec certitude. Les modèles se différencient selon leur ornementation ou son absence :

- Les petits pots à décor "mouluré " (fig. 15). Vingthuit exemplaires complets ou partiels sont identifiés. Les décors de moulures espacées (cordons encadrés) se concentrent sur la partie supérieure du récipient, avec un développement vers la partie inférieure de la panse dans un certain nombre de cas. Il en va de même pour le lustrage. Les fonds sont plats ou légèrement soulevés, avec ou sans bourrelet d'assise. Le rapport hauteur/largeur est de 0,85 , même si celui d'un exemplaire n'est que de 0,75. Ils sont majoritairement réalisés en poterie commune, puisque seul un vase est en proto-onctueuse. À noter 

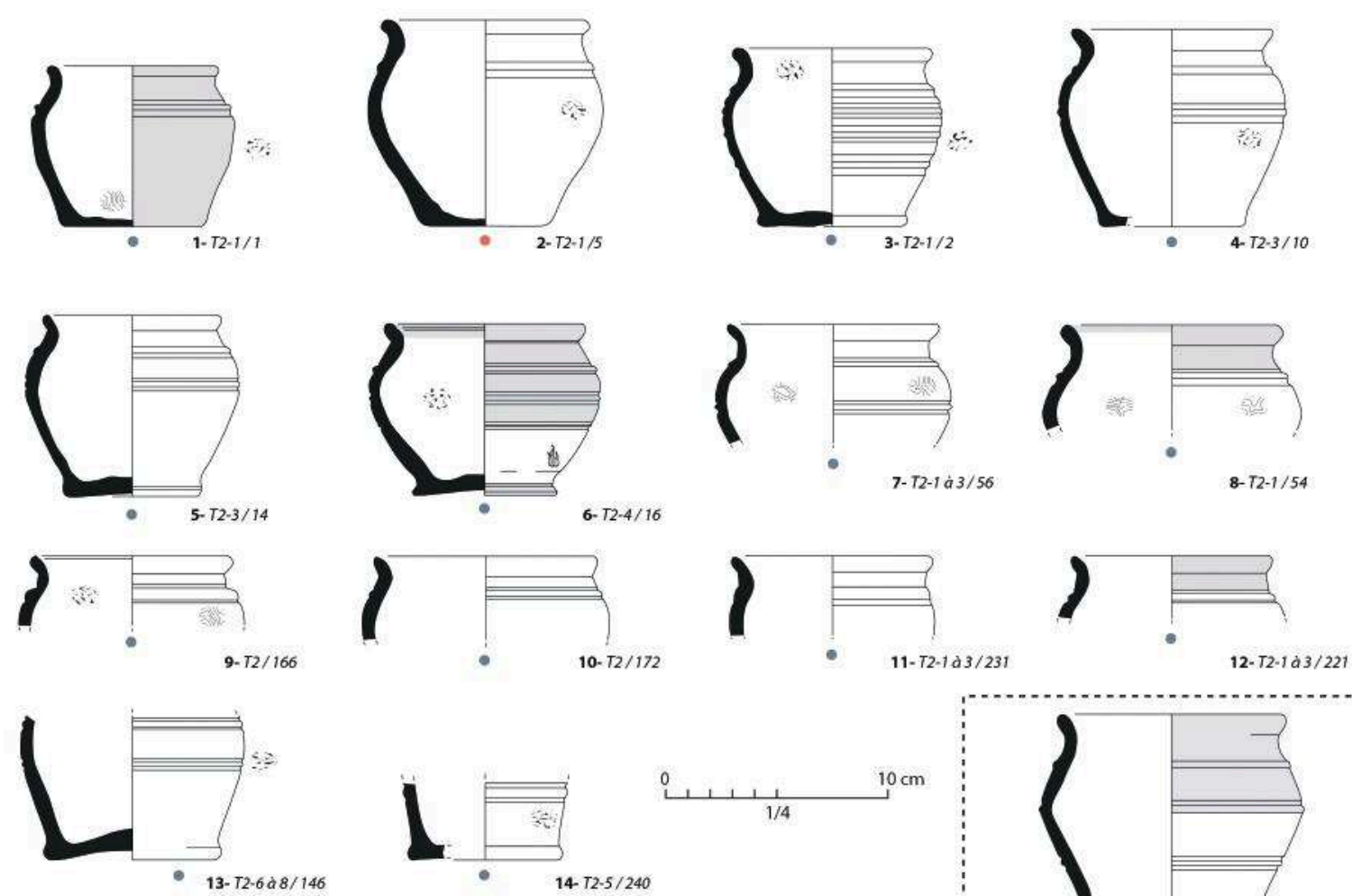

14. $T 2-5 / 240$
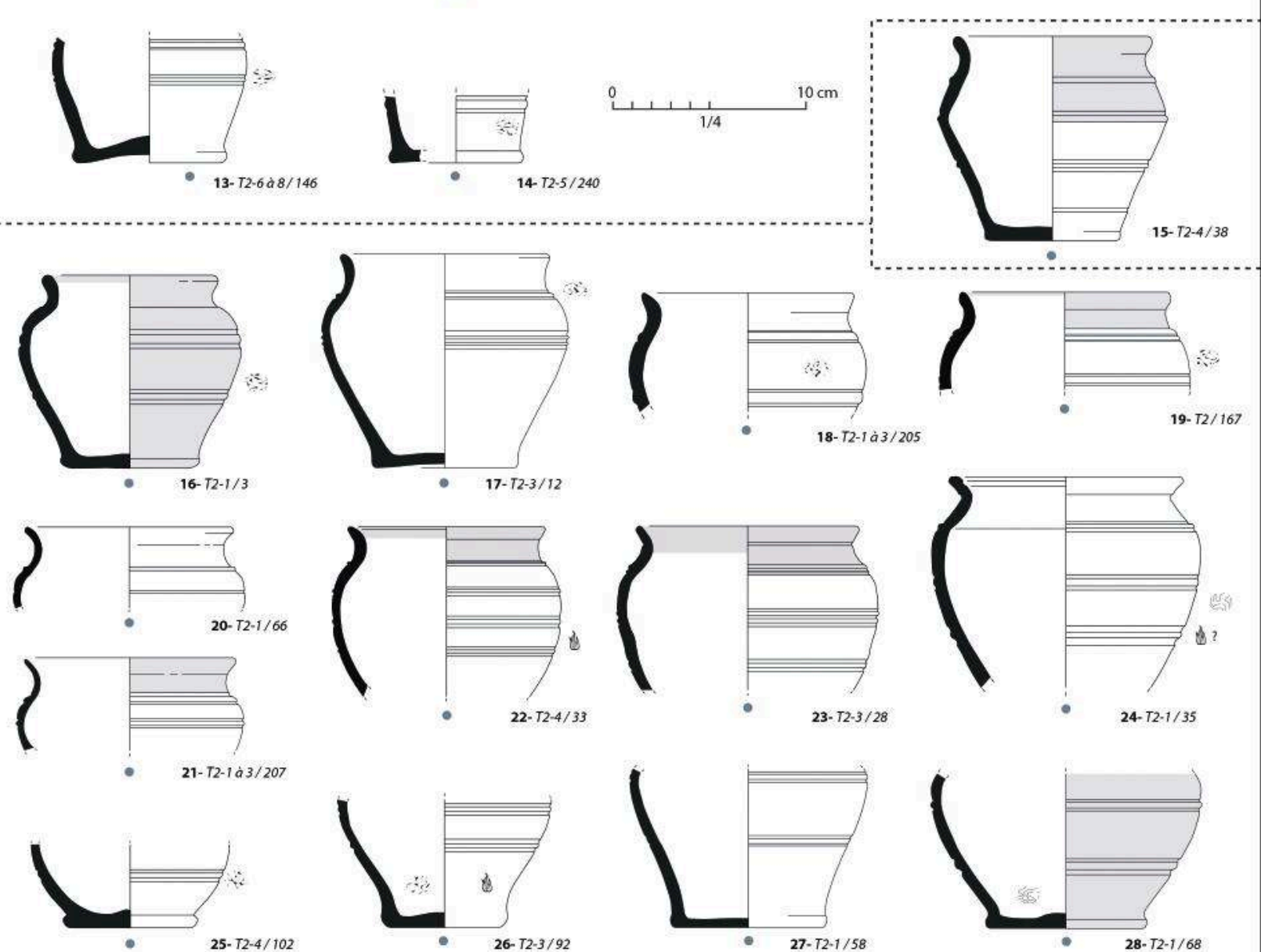

- Poterie commune

- Poterie proto-onctueuse

Surface lissée

Surface lustrée

$\because \quad$ Traces de suie

is. Usure, surface abîmée

- Traces de coup de feu

Figure 15 : Parc-ar-Groas : les petits pots à décor « mouluré ».

Figure 15: Parc-ar-Groas: the small jars with grooved-cordon decorations. 
parmi ce groupe de petits pots moulurés, la présence d'un vase d'allure plus biconique (fig. 15-15).

- Les petits pots à décor cannelé (fig. 16). Les dix-sept récipients reprennent le même schéma morphologique que le type précédent. Le décor se limite ici à une ou deux cannelures dans le haut du vase, généralement au niveau de l'épaulement. La part des productions en proto-onctueuse est plus présente, bien que minoritaire. Quelques pots à large rebord éversé (fig. 16 bas), toujours en protoonctueuse, peuvent être dotés d'une fine cannelure labiale interne.

- Les petits pots à cordon simple au-dessus de l'épaule (fig. 17). Quatorze vases ou parties supérieures de vases possèdent un simple cordon à la base du col, au-dessus du diamètre maximal de l'épaulement. Une cannelure peut éventuellement souligner ce cordon. Seuls deux récipients livrent un profil complet dont le rapport hauteur/largeur varie de 0,85 à 0,92 .

- Les petits pots sans décors (fig. 18). Du point de vue technologique, la tendance s'inverse puisqu'ici, les productions en pâte proto-onctueuse sont majoritaires. Les profils sont en esse avec une encolure parfois peu différenciée. Les rapports hauteur/largeur sont compris entre 0,7 et 0,85 . Le lustrage est moins présent.

Typologiquement, cet ensemble de petits pots s'apparente à plusieurs modèles bretons, sans exhaustivité, tant le site révèle une variété d'individus. De plus, la plupart des comparaisons concerne des familles de vases se déclinant en récipients de différentes dimensions et/ou plusieurs sous-types. Or, à Parc-ar-Groas, il s'agit presque exclusivement de récipients de petite, voire de très petite taille (cf. infra, 4.). Régionalement, les principaux rapprochements s'orientent vers les types 59 (milieu II ${ }^{\mathrm{e}}$ à fin I ${ }^{\text {er }} \mathrm{s}$. av. n. è.) et $61 \mathrm{~b}$ (dernier quart $\mathrm{III}^{\mathrm{e}}$ à troisième quart $\mathrm{I}^{\mathrm{er}} \mathrm{s}$. av. n. è.), si l'on tient compte de leur profil général et de leurs caractéristiques morphologiques (Cherel et al., 2018, fig. 12 et p. 285 à 287). Pour les exemplaires à cordon simple au-dessus de l'épaule, le type 85a peut être cité en référence (Cherel et al., 2018, fig. 19 et p. 298). Il est lui aussi daté des $\mathrm{II}^{\mathrm{e}}-\mathrm{I}^{\mathrm{er}} \mathrm{s}$. av. n. è. Des modèles équivalents se retrouvent jusque dans les Pays de la Loire (type 53b) ou en Normandie (Cornec et al., 2018, fig. 35 et p. 420)

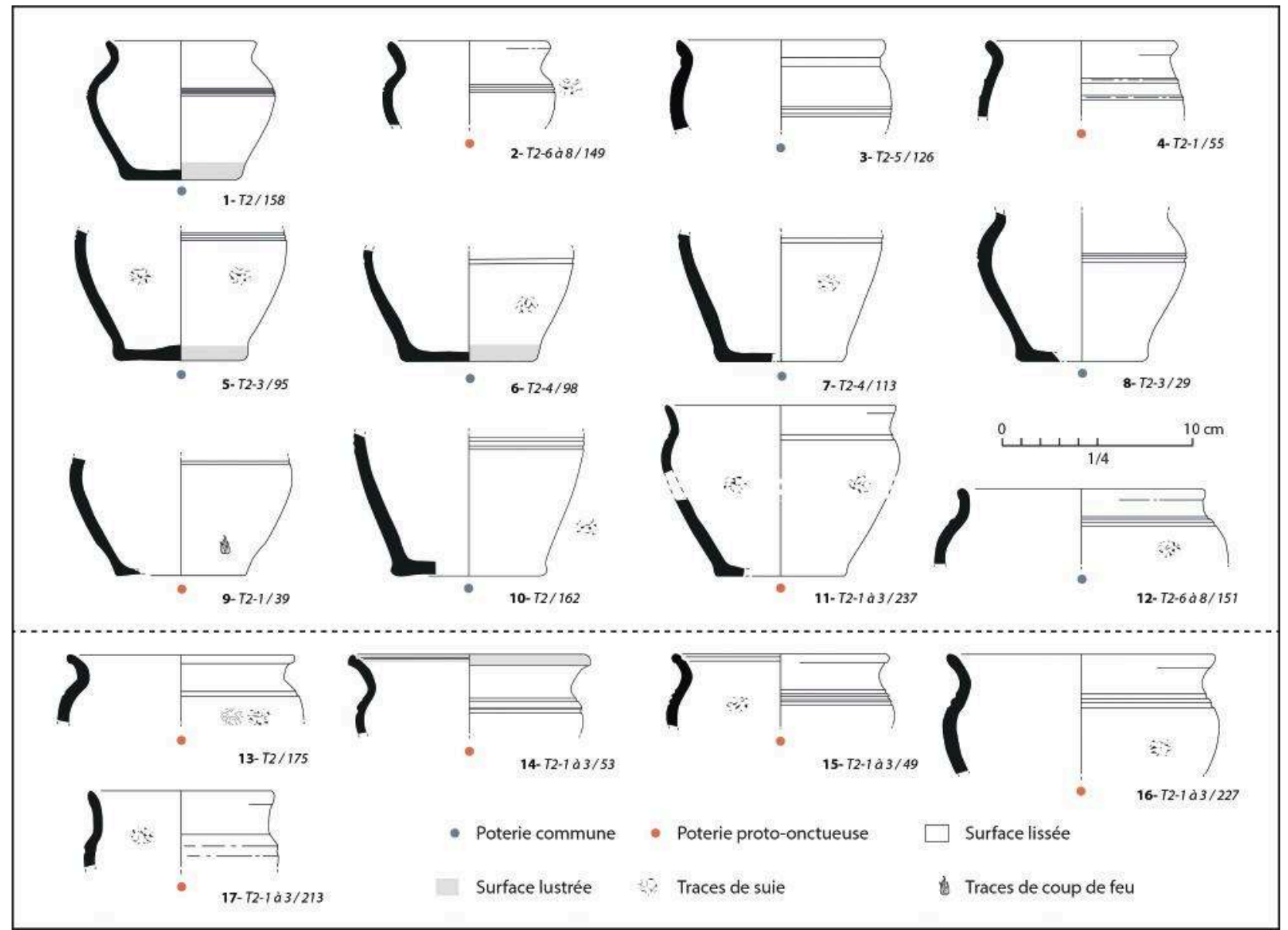

Figure 16 : Parc-ar-Groas : les petits pots à décor cannelé. 


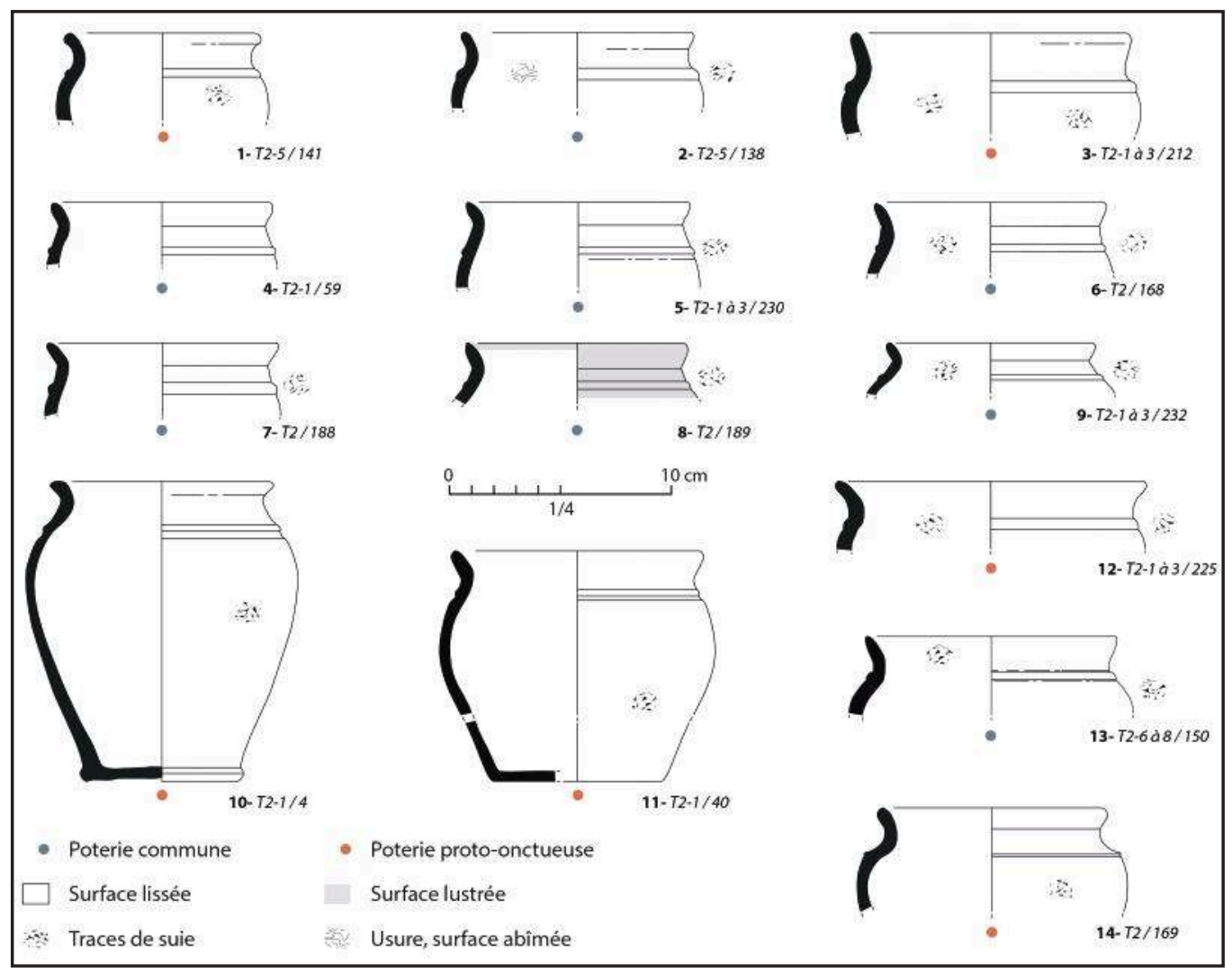

Figure 17 : Parc-arGroas : les petits pots à cordon simple audessus de l'épaule.

Figure 17: Parc-arGroas: the small jars with single cordon above the shoulder.

à la même période. Quant aux vases cannelés à large bord éversé, ils s'intègrent aux formes $\mathrm{H} 3-1-2 / 3 a$ et $3 \mathrm{~b}$ et H3-2-2/3a de l'agglomération de Kergolvez de la fin du $\mathrm{II}^{\mathrm{e}}$ s. au milieu du $\mathrm{I}^{\mathrm{er}}$ s. av. n. è. (Le Goff, dir., 2014, fig. 857 et 859), forme également fréquente au Braden I ou à Kervouyec II.

Ces modèles de petits pots sont relativement fréquents sur les habitats de La Tène finale, bien que découverts sous la forme d'individus relativement isolés. À Quimper, ils sont attestés au Braden I (Faulon, 1994, planche 15), au Braden II (Le Bihan et al., 1987), à Kergolvez (Le Goff, dir., 2014, fig. 857 et 859), aux Hauts-de-Penvillers (Le Bihan, 1997, fig. 16 et 37). Au-delà (cf. infra, fig. 30), ils se retrouvent à Huelgoat (Finistère) "Le Camp d'Arthus " (Daire, 1992, planches XXI-2 et 3), à Carantec (Finistère) " Île Callot " (Daire, 1992, planche XXI-4), à Pluguffan (Finistère) «Ti Lipig " (Le Gall et Paranthoën, 2020, fig. 351, 352, 354 et 356), à Paule (Côtes-d'Armor) "Camp de Saint-Symphorien » (Menez, 2008, fig. 236, 257 et 305), à Plumaugat (Côtesd'Armor) "Saint-Pierre " (Ah Thon, 2018, fig. 180), à Saint-Jacut-de-la-Mer (Côtes-d'Armor) "Les Ébihens " (Daire, 1992, planche XX-7), à Inguiniel (56) « KervenTeignouse » (Tanguy, 2006, fig. 30 et 38; Tanguy, 2011, fig. 12), à Ménéac (Morbihan) "Val Bodron " (Le Gall, 2015, fig. 150), à Erbrée (Ille-et-Vilaine) «La Huperie »
(Durand, 2017, fig. 149), à Gévezé (Ille-et-Vilaine) «La Croix du Vivier " (Ah Thon, dir., 2019, fig. 127) ou à Fay-de-Bretagne (Loire-Atlantique) "L'Alnais " (Daire, 1992, planches XX-3 à 6), etc. La plupart de ces exemples sont, dans le détail, comparables à ceux de Parc-ar-Groas, à l'image de celui de Gévezé et du vase fig. 16-11, de celui de Plumaugat et du vase fig. 16-1, de celui d'Erbrée et du vase fig. 15-1, de ceux d'Huelgoat et des vases fig. 18-1 à 10 par exemple (cf. infra, fig. 25). Toutefois, aucun de ces établissements ne livre de telles concentrations ou de telles variétés de petits pots.

\section{Les autres pots fermés}

Quelques pots fermés de plus grande taille complètent les formes hautes (fig. 19). Ils sont matérialisés par six fragments de rebords de vases à profil en esse. L'un d'entre eux se distingue par sa surface externe graphitée (fig. 19-4). Le plus grand des pots est décoré d'une fine cannelure labiale interne et d'une cannelure externe à la base de l'encolure (fig. 19-6). Ces deux exemplaires sont réalisés en pâte commune tandis que les quatre autres sont en proto-onctueuse. L'ensemble est complété par sept fonds de dimensions supérieures aux autres (cf. infra, 3.3.5.). Ces fonds, majoritairement fabriqués en argile commune, appartiennent à d'autres récipients que les fragments de rebords. 

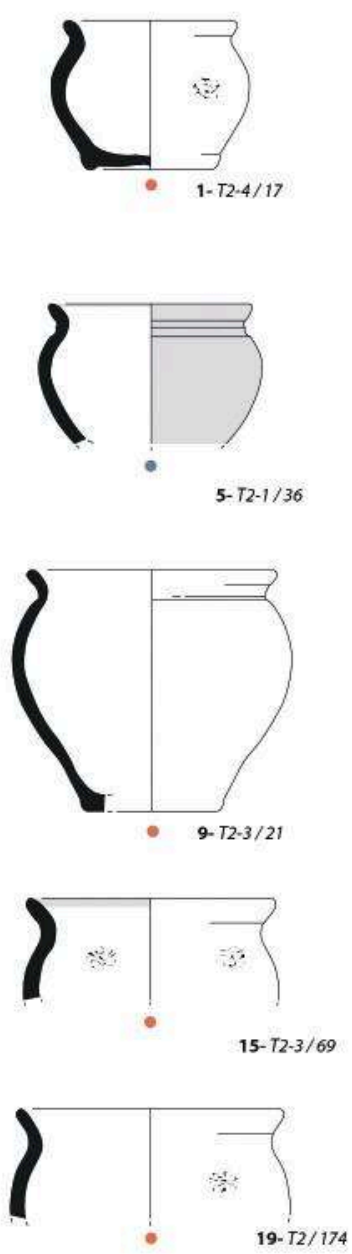
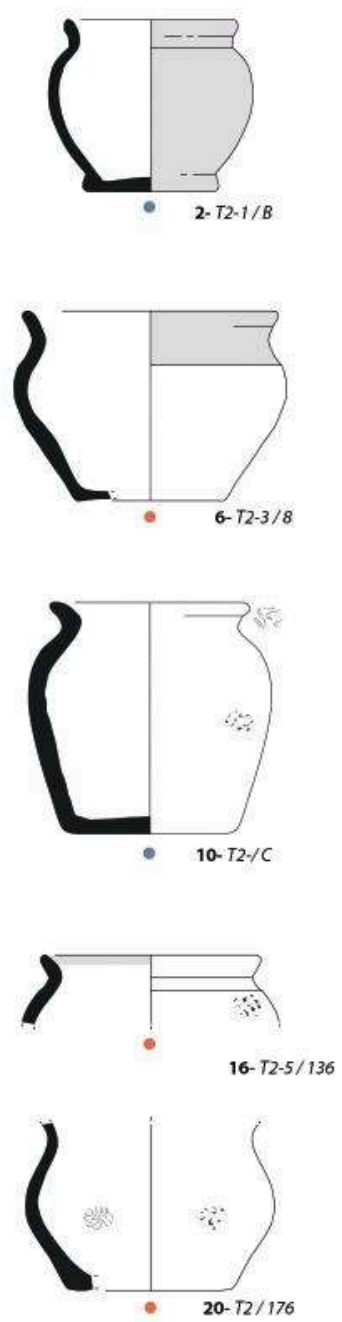

$16-72-5 / 136$

- Poterie proto-onctueuse

Usure, surface abîmée
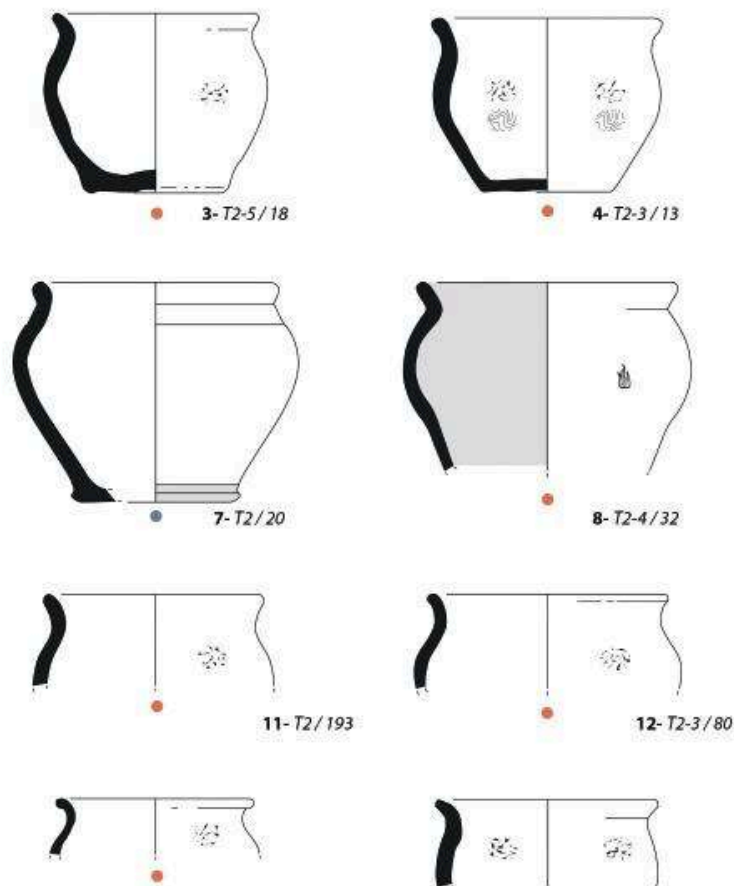

13- $T 2-1 d 3 / 224$
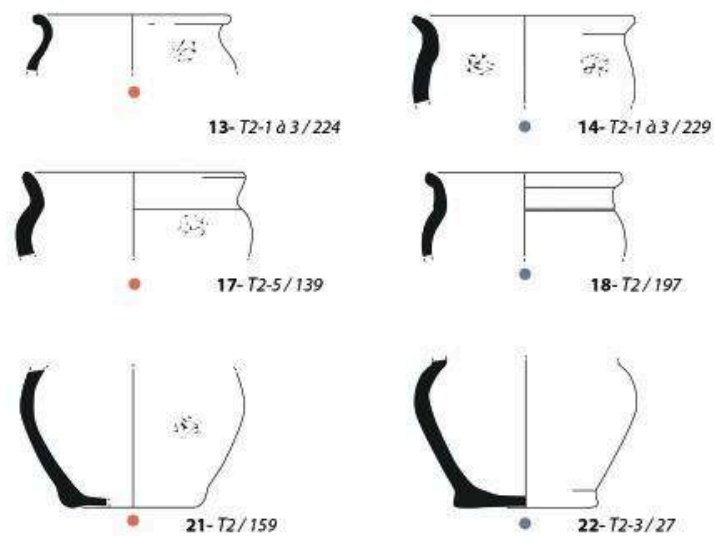

Surface lissée

Traces de coup de feu
Surface lustrée

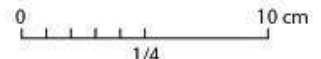

Figure 18 : Parc-ar-Groas : les petits pots sans décors.

Figure 18: Parc-ar-Groas: the plain small jars.

\section{Les fonds}

Quatre-vingt-deux fragments de fonds de petits vases s'ajoutent à l'ensemble de petits pots déjà présentés. Si ces fonds peuvent être classés en fonction de leur ornementation ou de leur morphologie, ils ne peuvent être rattachés à ces mêmes pots, ni à une variante particulière.

Le premier groupe rassemble les fonds de pots cannelés (fig. 20). Ils se sous-divisent en fonction de la partie inférieure de la panse : base tronconique, base convexe, base cintrée. Un exemplaire à large assise débordante est orné de cannelures concentriques sous le fond.
Le second groupe réunit les fonds sans décors (fig. 21 et 22). Là encore, la nature du bas de panse permet des déclinaisons (base cintrée ou tronconique), ainsi que la présence d'un bourrelet d'assise (fond plat ou fond soulevé).

Les diamètres des fonds sont globalement compris entre 6 et $9,5 \mathrm{~cm}$, même si quelques exemplaires atteignent $10,5 \mathrm{~cm}$. Leur gabarit est conforme à ceux observés sur les petits pots dont les diamètres des fonds varient de 5,5 à $8,5 \mathrm{~cm}$, avec une moyenne de $7 \mathrm{~cm}$. Les fonds dont l'assise dépasse $8,5 \mathrm{~cm}$ semblent toutefois appartenir à une catégorie de pots intermédiaires entre les petits (cf. supra, 3.3.3.) et les grands pots (cf. supra, 3.3.4.), dont les 


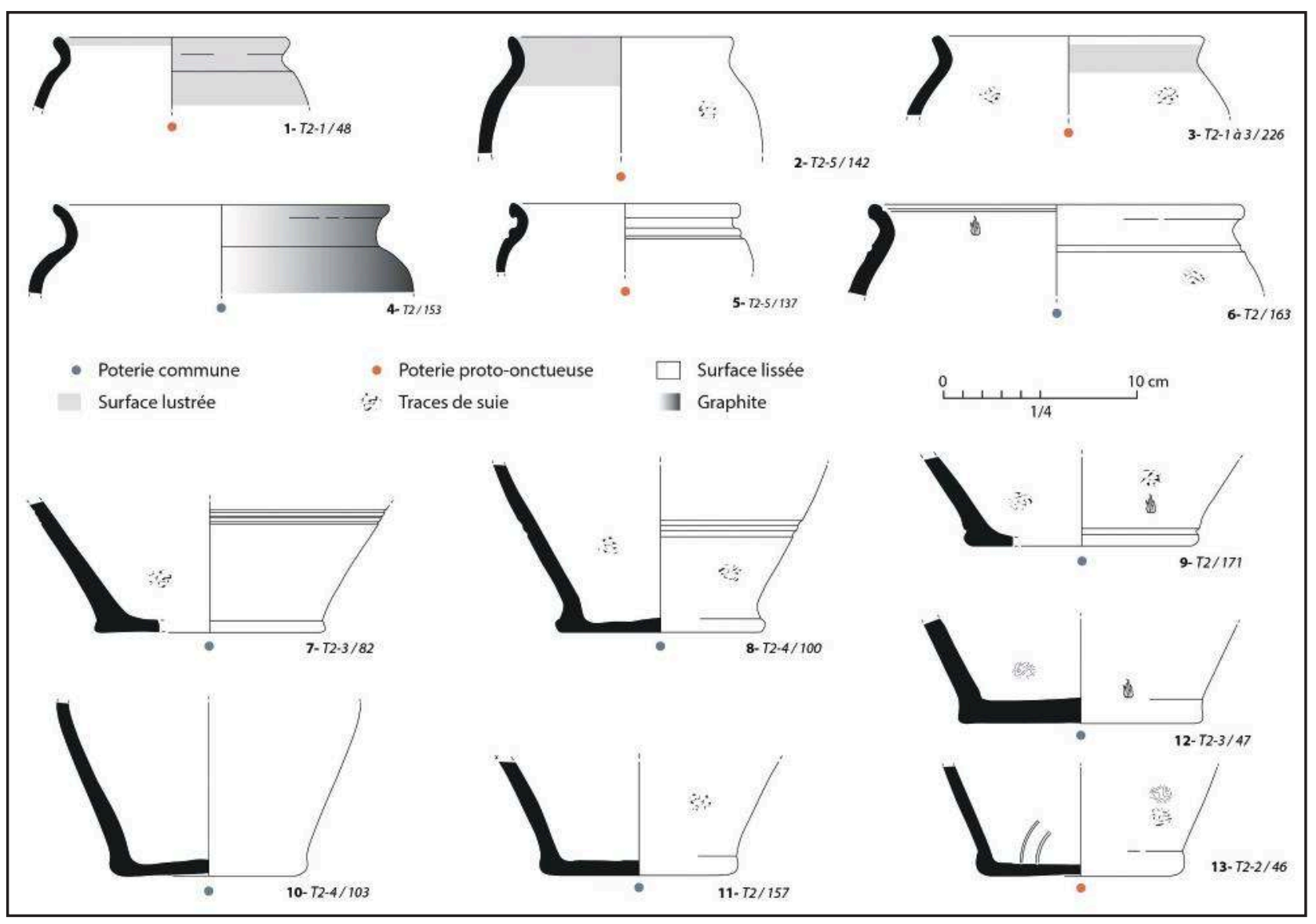

Figure 19 : Parc-ar-Groas : les autres pots.

Figure 19: Parc-ar-Groas: the other jars.

rebords manquent. Là encore, ces observations montrent une détérioration du dépôt d'origine.

\section{ANALYSE DES POTERIES DU DÉPÔT}

Les poteries composant ce dépôt autorisent un certain nombre d'observations sur leur état et leur utilisation. Toutefois, leur interprétation peut être délicate, que ce soit à propos des vases eux-mêmes ou de leur fonction, tant les données sur cette phase du site sont lacunaires. L'étude des relations à propos des ensembles de céramiques mis au jour sur les sanctuaires de la fin de l'âge du Fer à partir de l'exemple de Mirebeau-sur-Bèze en Côte-d'Or (Barral, 2015) offre un éclairage particulier sur le lot de Parc-arGroas, ainsi que des outils méthodologiques pour mieux l'appréhender. Afin d'argumenter en faveur de la nature cultuelle de l'établissement gaulois de Parc-ar-Groas, de prime abord sujette à caution sur la seule base des maigres vestiges immobiliers, il convient de reprendre point par point les données livrées par le lot de céramiques.

La première remarque concerne la qualité des vases. La grande majorité des récipients ne présente que très peu de traces d'utilisation ou d'usure. Leur état de conservation est très satisfaisant bien qu'ils ne soient jamais intacts; certains d'entre eux semblent presque neufs. Cela est d'autant plus net sur les surfaces internes qui conservent leur qualité de lissage soigné, voire de lustrage. Les quelques surfaces abîmées le furent essentiellement après usage lors du rejet dans le fossé (cf. infra). Les autres stigmates présents sont des traces de suie visibles sur nombre de vases. Il ne s'agit cependant là que de fines pellicules localisées et non de croûtes ou de caramels alimentaires tels que l'on peut en observer sur les vases de cuisson des habitats. Elles indiquent seulement que les vases ont été en contact avec une source charbonneuse ou de la fumée. De telles traces à la fois sur les surfaces externes, mais aussi internes de certains récipients, montrent que certaines de ces interactions ont pu se manifester après le bris ou au moment de leur enfouissement. Ce bilan préalable constitue un premier critère distinguant ce lot des assemblages domestiques issus de rejets, de mise au rebut de récipients usés, cassés voire réparés.

D'un point de vue fonctionnel, le nombre de catégories de récipients attestées dans le dépôt est assez limité. 

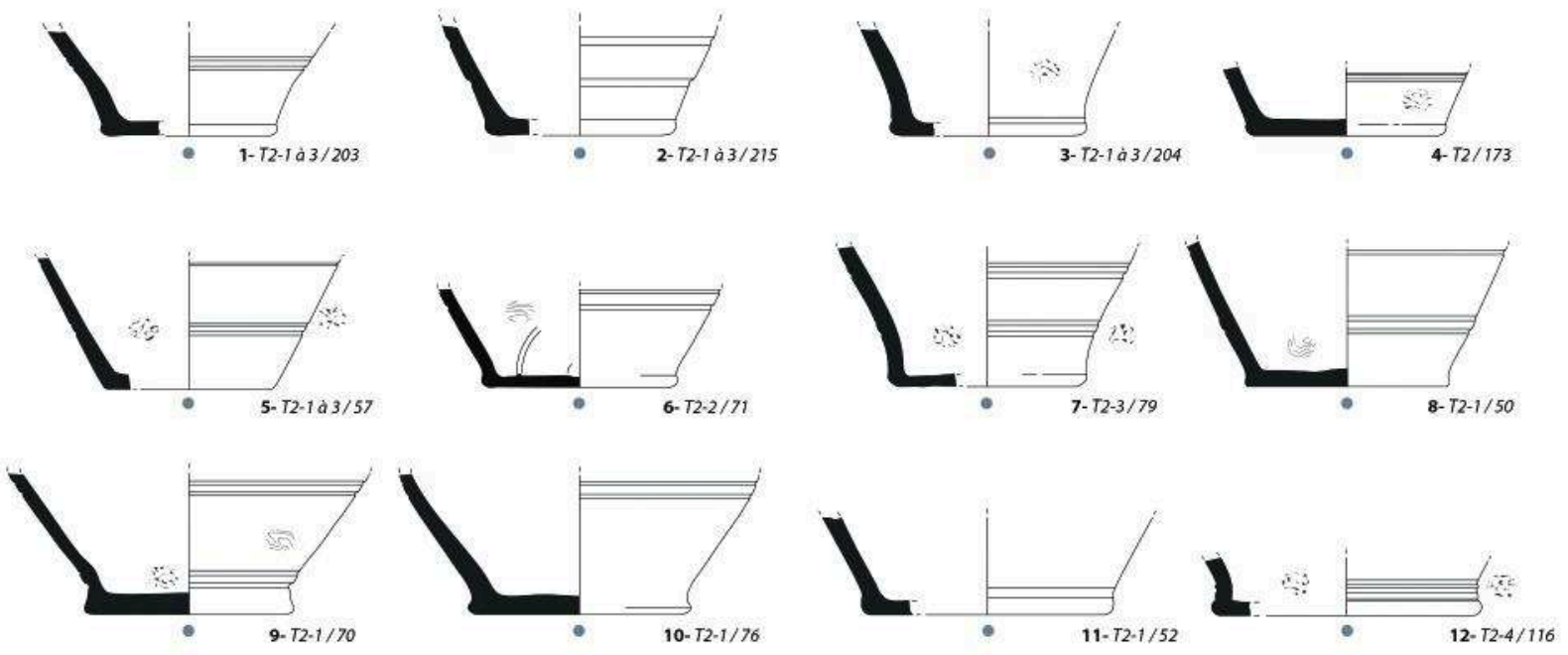

Fonds à bas de panse tronconique
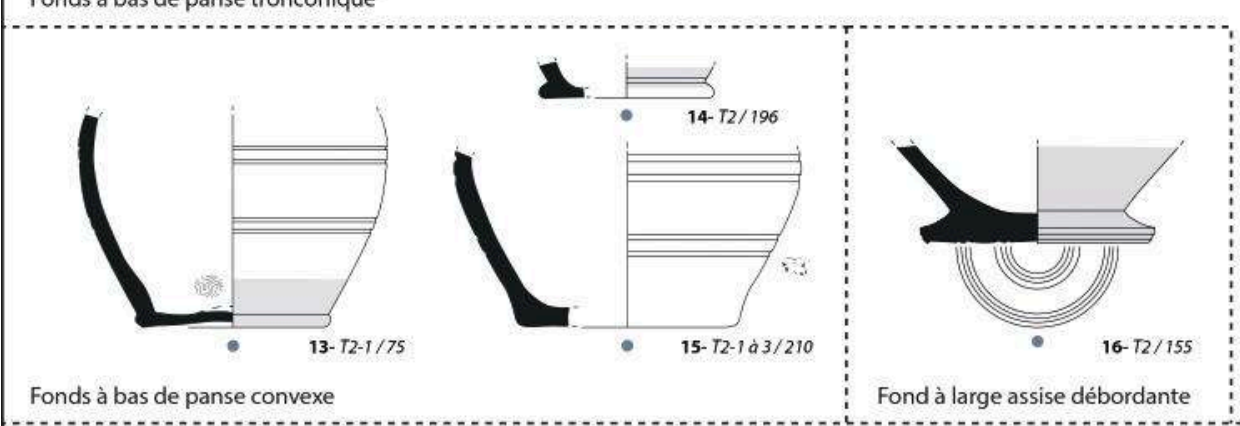

- Poterie commune

- Poterie proto-onctueuse

Surface lissée

Surface lustrée

Traces de suie

Usure, surface abîmée

b Traces de coup de feu Fonds a bas de panse cintrée
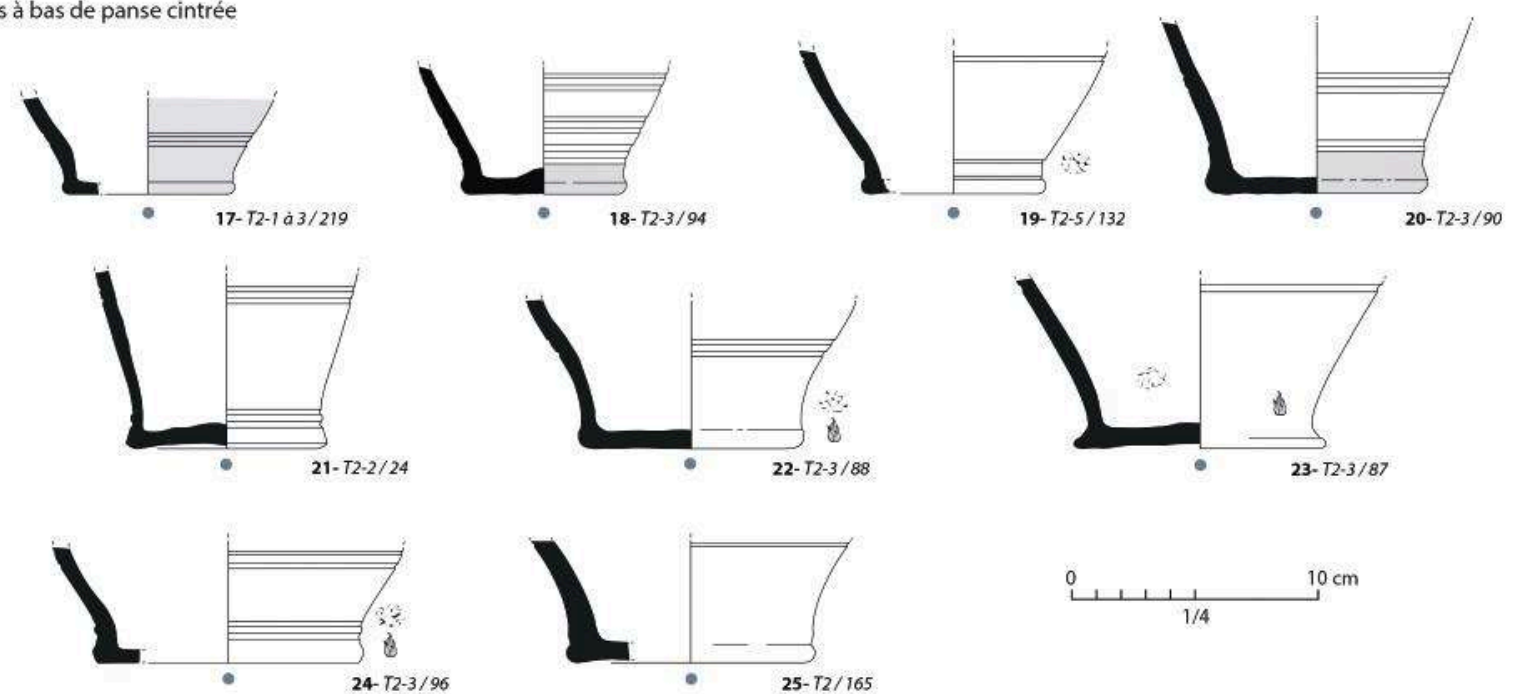

Figure 20 : Parc-ar-Groas : les fonds de pots cannelés.

Figure 20: Parc-ar-Groas: the small grooved jar bases.

Il s'agit de vaisselle de consommation ou de présentation (jattes basses ou moyennes, gobelets) ou de petits pots aux dimensions relativement modestes. Le calcul des contenances maximales des vases à profil complet ou quasiment complet (du fond au sommet de la lèvre) par la technique du cumul des volumes des troncs de cône figurant l'espace interne des récipients, montre qu'il n'y a pas véritablement de taille standard. Les contenances évoluent de 14,5 à $77 \mathrm{cl}$ pour les petits pots d'allure trapue (fig. 23 gauche). Une distinction arbitraire peut toutefois être faite entre les très petits pots au volume interne inférieur à $50 \mathrm{cl}$ et les petits pots au volume supérieur à cette valeur. Pour les 


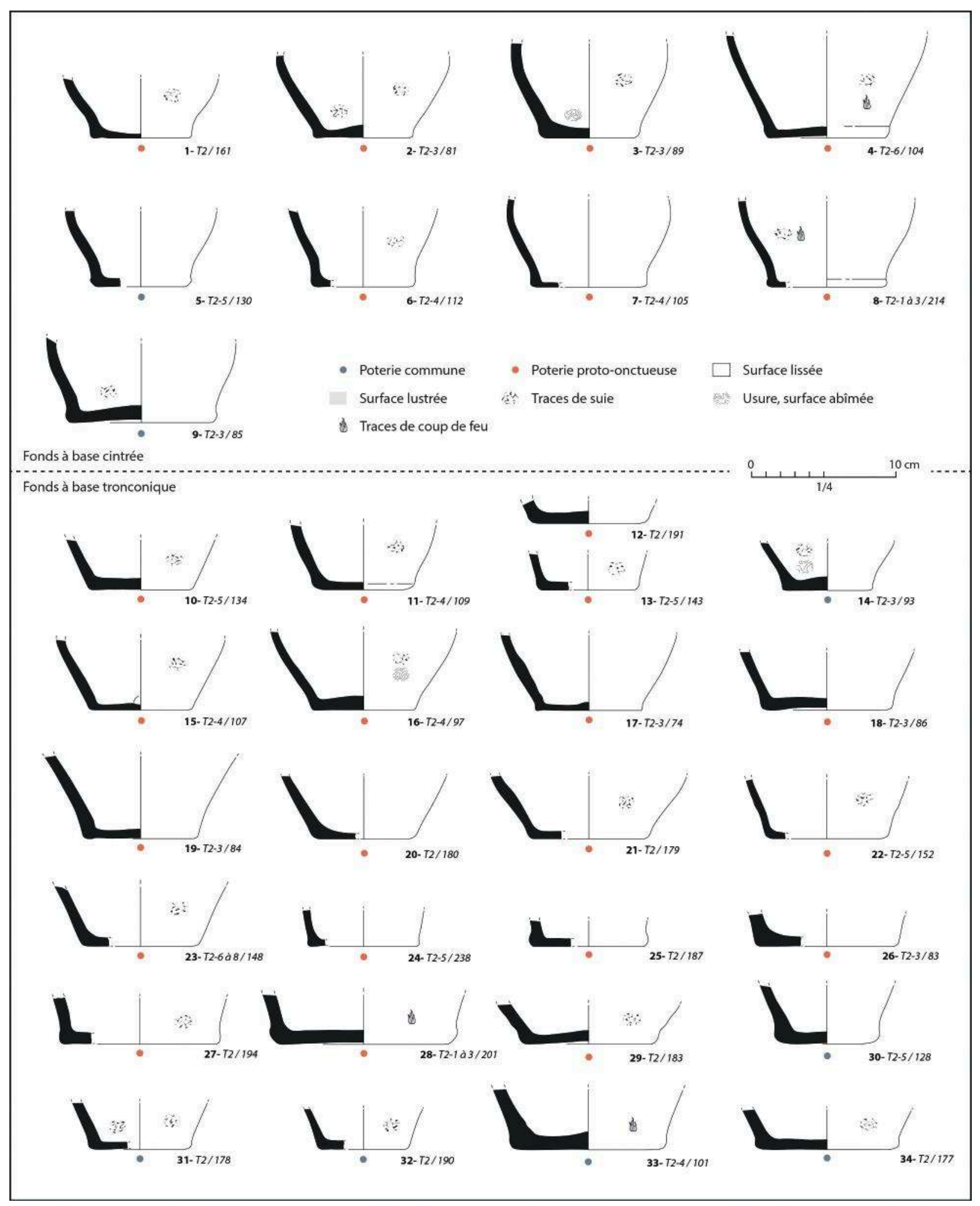

Figure 21 : Parc-ar-Groas : les fonds de pots sans décors.

Figure 21: Parc-ar-Groas: the plain jar bases.

quelques formes hautes de pots au profil plus élancé, les contenances sont de 87 et $102 \mathrm{cl}$. On note que la contenance de ces très petits et petits pots est assez voisine de celle des gobelets, entre 27 et $42 \mathrm{cl}$ (fig. 23 haut à droite), et de celle des jattes de faibles dimensions dont les valeurs calculables vont de 34 à 56 cl (fig. 23 centre à droite). Ces 


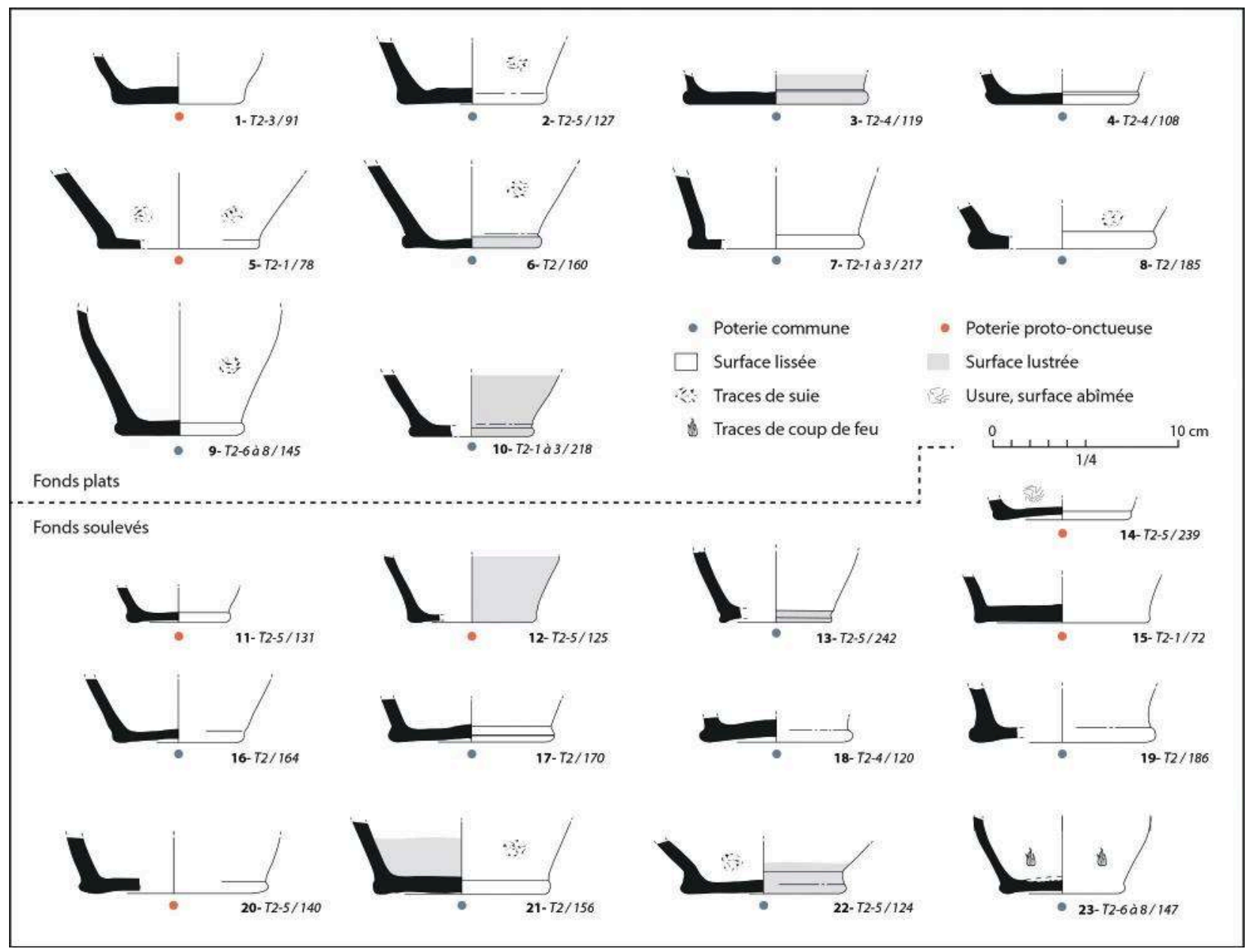

Figure 22 : Parc-ar-Groas : les fonds de pots sans décors.

Figure 22: Parc-ar-Groas: the plain jar bases.

caractéristiques de contenance modeste président donc à la composition du lot de poteries du fossé T. 2, les pots et les jattes de plus grandes dimensions constituant alors des formes complémentaires secondaires parmi les modèles de récipients. Ainsi, un phénomène de sélection apparaît, avec un mode d'assemblage distinct des répertoires domestiques issus des habitats contemporains. Cette surreprésentation de petits modules (fig. 24) traduit " une sélection opérée au sein du répertoire habituel » (Barral, 2015).

Cette prédominance des petits volumes constitue-telle une exception, un particularisme du site de Parcar-Groas? Oui d'un point de vue quantitatif, non d'un point de vue typologique. Le classement des formes et les descriptions morphologiques montrent que tous les vases présents trouvent des équivalents sur les sites d'habitats quimpérois et régionaux (fig. 25). Sur cet aspect, la fonction religieuse du site n'influe pas sur l'originalité de l'ensemble de poteries. De telles constatations ont été faites sur le site protohistorique de Mez-Notariou à en contexte rituel ne diffèrent pas de celles mises au jour sur l'agglomération ou les habitats attenants, que ce soit au cours du Bronze moyen-final I (Le Bihan et Villard, 2010, fig. 110) ou durant le Bronze final IIIb-La Tène ancienne (Le Bihan et Villard, 2020; Villard et Le Bihan, 2020, chapitre 9, fig. 177, 178 et 180). C'est également le cas au cours de l'Antiquité entre le mobilier de Parcar-Groas, des phases III et IV notamment, et celui de l'agglomération secondaire de Quimper-Locmaria ou des habitats ruraux environnants (Villard, 2012a et b). Il en va de même dans le domaine funéraire où une variété de vases d'usage courant est utilisée comme urnes à crémation. C'est le cas dans la nécropole antique quimpéroise de Creac'h-Maria (Le Bihan et Villard, 2012) ou dans certaines nécropoles de l'âge du Fer comme à Kerancoat ou à Kerjaouen (Villard et al., 2006). Ce qui fait véritablement l'originalité du dépôt de Parc-ar-Groas, c'est la concentration d'environ cent-cinquante de ces petits pots sur une surface de $8 \mathrm{~m}^{2}$ au sein d'une même structure. En règle générale, ce type de récipients est recensé au cas par cas 


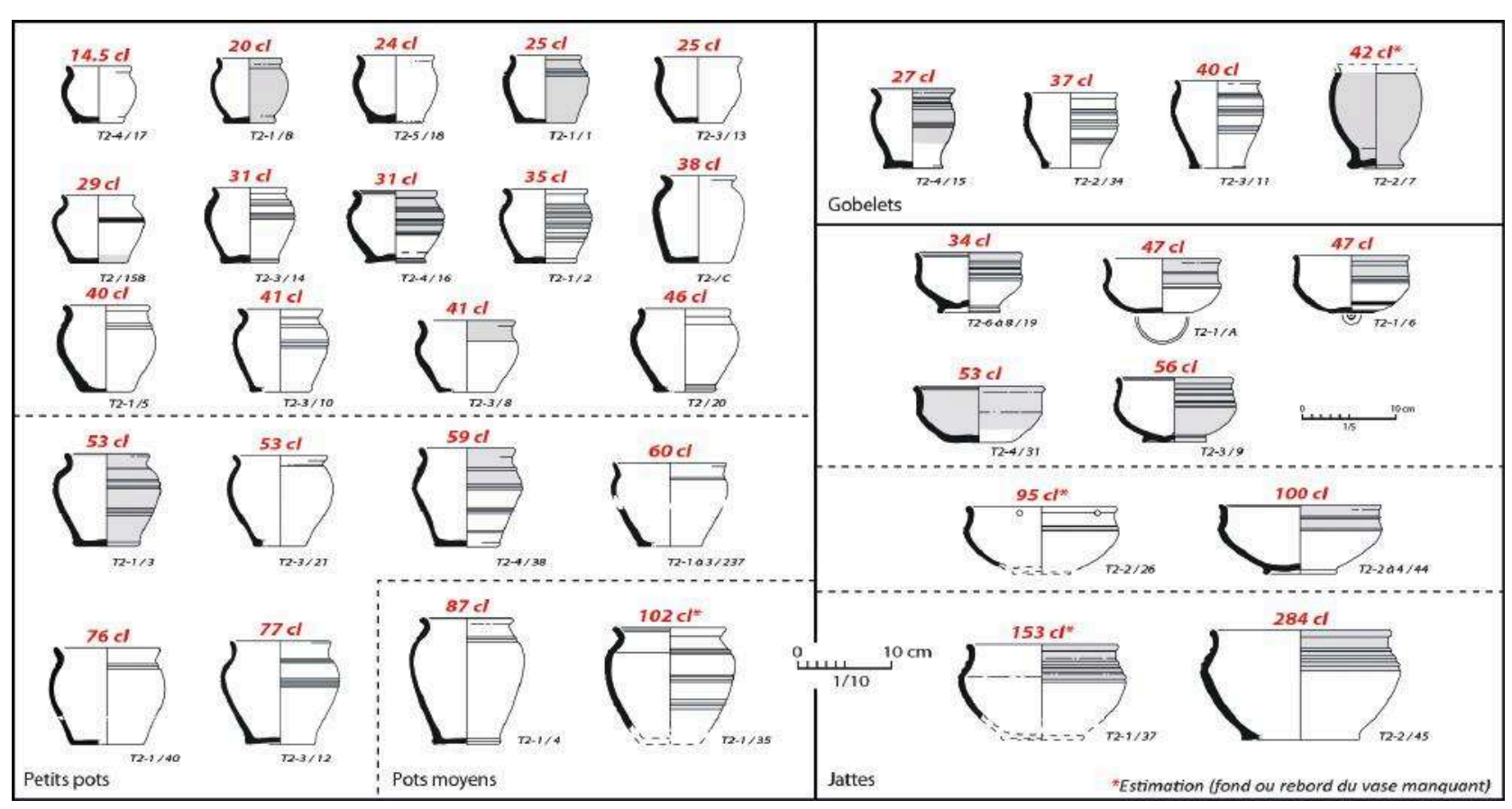

Figure 23 : Parc-ar-Groas : classement par contenance des petits pots, des gobelets et des jattes (en centilitre).

Figure 23: Parc-ar-Groas: distribution of the small jars, beakers and bowls by capacity (in centilitre).

sur les différents sites de comparaison mentionnés dans la présentation typologique. Si une quinzaine d'exemplaires est attestée à Kergolvez, ils sont répartis sur une fouille de 3,2 ha au cour d'une agglomération gauloise (Le Goff, dir., 2014). La concentration de Parc-ar-Groas semblerait donc davantage liée au statut du site : un établissement cultuel, type de site sur lequel des manipulations particulières et bien ciblées peuvent exister. Ce phénomène d'accumulation, d'amas de récipients aux critères ou au module communs, entre dans la définition des ensemble de vaisselle de sanctuaires ou tout au moins de sites à vocation cultuelle (Barral, 2015). Cette sélection d'une catégorie de petits récipients dans la composition du lot, ainsi que leur utilisation, peuvent aisément entrer dans le cadre de pratiques rituelles. Elle rappelle l'exclusivité et la surreprésentation des formes de consommation et de présentation dans l'assemblage du mobilier des vestiges à caractères rituels de Mez-Notariou au premier âge du Fer (Villard et Le Bihan, 2020, chapitre 9). Des observations similaires sont également faites à Mirebeausur-Bèze où " la représentation des modules de vases, des catégories techniques et des types morphologiques met en lumière des différences sensibles entre dépotoirs domestiques et des ensembles de rejets d'activité cultuelle et, en revanche, fait apparaître des affinités claires entre sanctuaires et nécropoles du point de vue des sélections opérées " (Barral, 2015). Des vases de petites dimensions y sont abondants et sont également associés à des séries de vases miniatures (Barral, 2015, ill. 1-5/6 et ill. 2). Dans le cas de Mirebeau, cette dernière catégorie, probablement fabriquée spécifiquement pour une utilisation cultuelle, paraît caractéristique des sites de sanctuaires. À Quimper, la question de la présence de telles miniatures ne se pose que pour les plus petits pots à la contenance inférieure à 20-25 cl, au profil très compact. En ce qui concerne le lot de Parc-ar-Groas, il s'agit davantage d'un ensemble de petits vases que de vases miniatures (cf. supra). Les observations ne font pas état d'une telle production, ni d'une volonté de miniaturisation symbolique d'objets du quotidien. Au-delà de ces critères de taille, la question des offrandes individuelles, éventuellement modestes, est sous-jacente (cf. infra), et demeure au cours de l'Antiquité (Fauduet, 2020) autant que pour les périodes plus anciennes (Goussard et al., 2019). Nous nous heurtons aux limites de l'interprétation des gestes à caractère rituel.

Par certains aspects, le lot quimpérois pourrait également être comparé au dépôt de l'Alnais à Fay-deBretagne (Loire-Atlantique), recelant soixante-dix petits récipients enfouis dans une structure de bois en bordure d'un marais. L'interprétation de ce dépôt en contexte humide demeure toutefois délicate. L'une des hypothèses s'orienterait vers celle de récipients à offrandes d'un petit sanctuaire. Cependant, les datations ${ }^{14} \mathrm{C}$ et une réattribution du mobilier céramique datent cet ensemble du début de l'Antiquité et non pas de La Tène finale (Bouvet et al., 2003). Malgré tout, il s'agirait là d'un rare cas où la concentration de petits vases est mise en avant dans la définition d'un cadre rituel. Quoi qu'il en soit, à 


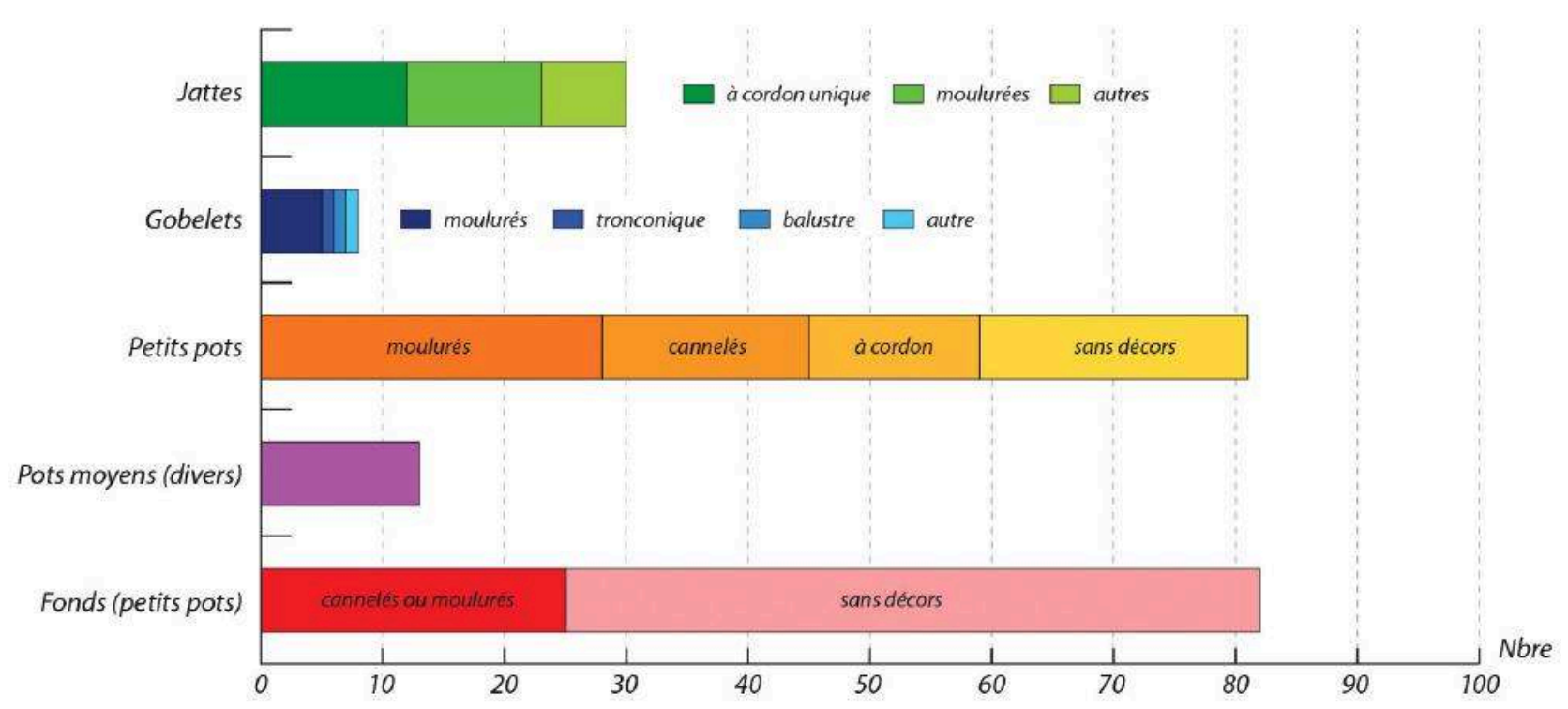

Figure 24 : Parc-ar-Groas : quantification des types et des modèles de récipients recensés dans le fossé gaulois.

Figure 24: Parc-ar-Groas: Quantification of types and shapes of vessels indentified in the Iron Age ditch.

Parc-ar-Groas, cette sélection de vases de faible volume et leur regroupement sont remarquables et diffèrent nettement des rejets domestiques de poteries observés sur les habitats, tant par le nombre que par la qualité de leur état de conservation. Il s'agit là d'un critère primordial pour la définition de la nature du lot et du site. Malheureusement, les mentions d'ensembles céramiques au sein des sanctuaires laténiens sont peu nombreuses, soit du fait de leur absence, soit par manque d'études spécifiques sur ce type de mobilier au profit de recherches sur des éléments métalliques par exemple. "Un bref examen de la bibliographie sur les sanctuaires et lieux de culte laisse apparaître [...] un déficit de sites et d'ensembles de mobilier céramique bien documentés et publiés [...] globalement, on ne peut qu'être frappé par le faible nombre d'attestations de véritables dépôts dans lesquels la vaisselle céramique entre pour une part importante [...] les dépôts organisés ou les amas intentionnels mobilisant des vases entiers et intacts, ou peu fragmentaires, sont finalement très peu nombreux dans la bibliographie relative aux sanctuaires » (Barral, 2015). Dès lors, l'étude de l'ensemble quimpérois trouve tout son sens en dépit de ce manque de références.

Se pose ensuite la question de la fonction de cet assemblage de récipients et des pratiques qui y sont associées. Les indices sont minces. La plupart des stigmates observés sur les vases semblent provenir de leur abandon ou de leur rejet sans qu'il soit possible de les rattacher à des pratiques ou à des gestes clairement définis. Quelques traces de brûlure sont visibles sur le bas de panse de quelques de suie a déjà été évoquée (cf. supra). Si les vases ont été au contact d'un feu, ils n'y ont pas été jetés à la fin d'une cérémonie pour une destruction ou une purification. Les traces seraient plus fréquentes et davantage marquées. Il n'est pas non plus certain que de tels stigmates aient été occasionnés sur le site lui-même dans la mesure où l'on ne sait pas s'il s'agit de vases réservés aux rites et conservés dans l'enceinte cultuelle, ou de vases apportés par les pratiquants depuis leur domicile. Une partie des traces peut donc être antérieure à l'usage rituel. Que les vases de Parc-ar-Groas soient identiques à des séries présentes sur les habitats ne contribue pas à une interprétation de leur usage religieux.

Par ailleurs, il apparait que les vases n’ont pas été déposés directement, soigneusement, dans le fossé dans le cadre d'un dépôt cérémoniel : s'y sont mêlés des pierres et des sédiments charbonneux. Des vases étaient certainement déjà brisés puisque même pour certains d'entre eux, profondément enfouis sous d'autres, une partie du récipient manque (profils incomplets). Par ailleurs, on ne relève aucune trace de bris spécifiques ou intentionnels assimilable à des bris mutilatoires rituels. Tout porte à croire qu'il s'agit plutôt d'un dépôt secondaire. Même si dans quelques cas l'imbrication de vases traduit un certain respect dans les gestes (cf. supra, fig. 7 et 10). La « découverte de trois poteries emboitées l'une dans l'autre, dans le comblement du fossé de l'enclos cultuel du sanctuaire de La Villeneuve-au-Châtelot » (Barral, 2015) présente de fortes similitudes avec le cas d'imbrication du petit pot T2-1/B et de la petite jatte T2-1/A de Parc-ar-Groas. 


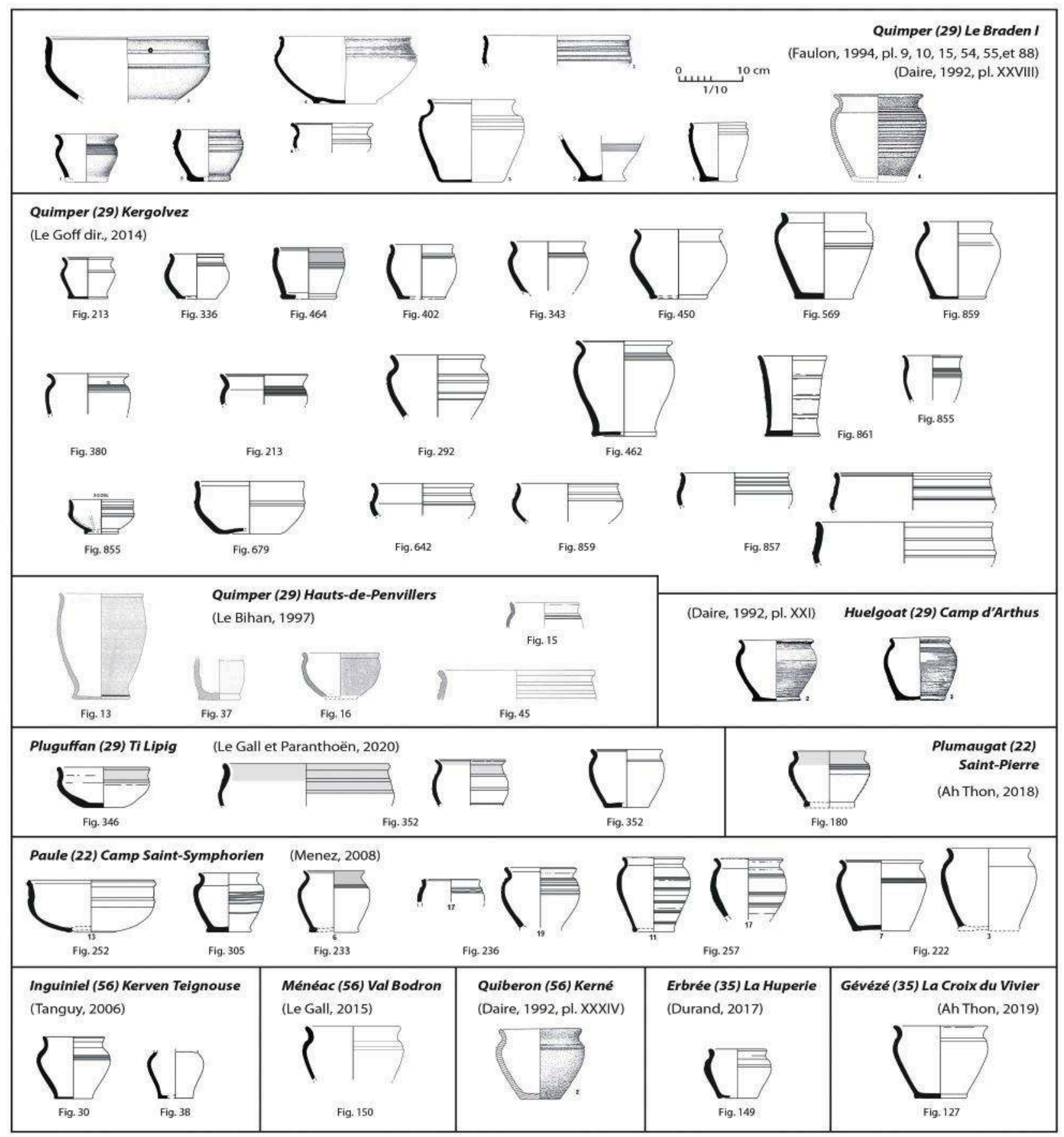

Figure 25 : Planche de comparaisons.

Figure 25: Comparaison plate.

L'association du dépôt de vases avec des terres charbonneuses n'est pas unique. Elle se retrouve à Mirebeausur-Bèze où le " processus de rejet relevant de l'entretien du sanctuaire peut être retenu pour des fosses qui renferment un sédiment charbonneux et des fragments de céramiques et autres objets. Le terme de fosses de nettoyage ou de vidange peut convenir..." (Barral, 2015). Ces observations rejoignent également celles faites sur les fossés antiques des phases III et IV (cf. supra, 1.2.3 et
1.2.4.). Au moment du scellement-abandon de ces derniers, la partie supérieure du comblement est constituée de couches très charbonneuses, recelant un très abondant mobilier, notamment céramique. Ces sédiments proviennent du déménagement interne du temenos et entérinent la sacralisation du mobilier avant la construction des aménagements de la phase suivante. Les vases ont donc dû être récupérés sur le site, puis rejetés dans le fossé T. 2 à un moment de l'histoire de l'établissement 


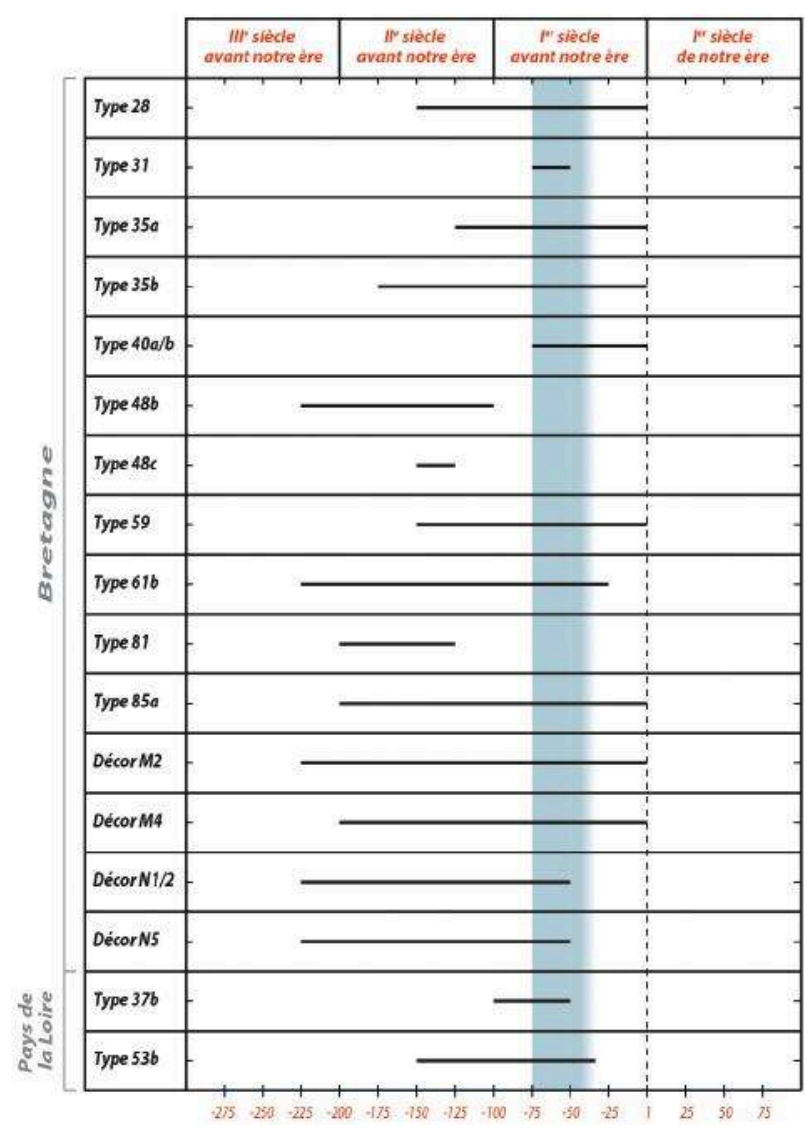

Figure 26 : Tableau de datation du lot du fossé T. 2.

Figure 26: Dating table of the ditch T.2 assemblage.

(cf. infra). L'érosion du sommet du fossé nous prive de renseignements déterminants à ce sujet, en particulier à propos d'une éventuelle fermeture de la tranchée analogue à celle du fossé T.3 par une couche d'arène de scellement (cf. supra, 1.2.3.).

En ce qui concerne les rites antérieurs à l'enfouissement, l'indigence des vestiges gaulois conservés ne permet que la formulation d'hypothèses. Ces quelques vestiges s'inscrivaient dans des aménagements plus vastes dont la nature demeure indéterminée. Seule la fosse S. 9 et ses restes de quartiers de bœufs sélectionnés et exposés (cf. supra, 1.2.1.) entre dans le cadre des activités observées sur les sanctuaires gaulois. Ces quartiers révèlent une activité sacrificielle sur le site, tel que cela se rencontre à Gournay-sur-Aronde par exemple (Brunaux et Méniel, 1983; Brunaux, 1986). Par la nature de ses sélections anatomiques de viande (thorax et cuisses), la fosse et son contenu rappellent les découvertes «effectuées [...] lors des fouilles du sanctuaire de Mirebeau (Côte-d'Or) [...]. Plusieurs fosses, implantées à proximité de bâtiments sur poteaux, ont livré quelques restes, entiers ou peu fragmentés, issus de la découpe d'un ou de quelques bovins. Cette pratique reste pour l'instant inexpliquée, mais donne lieu à une petite série de dépôts très particuliers et bien différents des restes de banquets trouvés en abondance dans les autres structures de cet important lieu de culte " (Le Bihan et Villard, 2012, p. 312; Méniel, 2016). Généralement, ces sacrifices d'animaux se déroulent durant des cérémonies collectives ou communautaires et s'accompagnent de banquets et/ou de libations (Arcelin et Brunaux, 2003). La typologie des vases présents ne paraît pas correspondre à une vaisselle de banquet, tant les jattes, écuelles et gobelets sont minoritaires par rapport à l'ensemble. On note par ailleurs l'absence de vases de cuisson ou de préparation des aliments. Ces absences ne sont toutefois pas exclusives puisque les vases du dépôt auraient pu servir « au transport dans le sanctuaire, à l'aide de vases adaptés, de préparations culinaires élaborées à l'extérieur, hypothèse émise pour des vases à col poissé à propos [de récipients des sanctuaires] de Gournay ou de Bennecourt " (Barral, 2015). Cependant, le format des vases de Quimper ne cadre pas plus, tant par leur contenance plus individuelle que collective, que par leur catégorie fonctionnelle qui nécessiterait le transfert de ces "rations " dans d'autres récipients pour la consommation, vases absents du répertoire. En revanche, ces récipients de faible contenance, qu'ils soient ouverts ou fermés, peuvent avoir été utilisés à l'occasion de libations au sens antique du terme : rituel consistant à verser quelques gouttes d'un liquide (vin, bière, hydromel, lait, huile...) sur le sol ou sur un autel en offrande à une divinité. Ces libations peuvent intervenir avant le sacrifice (sur l'animal par exemple) ou après (offrande, banquet ritualisé). Cette pratique est classique dans les religions de l'âge du Fer ou de l'Antiquité. Elle se retrouve aussi bien au premier âge du Fer à Vix en Côted'Or (Brunaux, 2000, p. 88) qu'à Corent dans le Puy-deDôme durant La Tène finale (Poux et Demierre, 2015). Ce dernier site livre également des ensembles de coupes ou vases à boire et des vases de petite taille aux côtés de dépôts d'amphores vinaires et de fosses dédiées aux libations. À Parc-ar-Groas, les informations manquent sur la nature des liquides qui auraient pu être utilisés, même si le vin reste le plus courant dans les sanctuaires gaulois. Les fragments d'amphores vinaires font défaut. Ceci est paradoxal puisque les amphores (gréco-italiques et Dressel 1) sont fréquentes sur tous les sites d'habitats quimpérois contemporains. Leur absence, constatée dans le fossé T. 2, n'est pas, a priori, exclusive, mais bien que les données sur l'organisation de l'établissement laténien de Parc-ar-Groas soient lacunaires, il est assez remarquable qu'elles fassent défaut sur l'ensemble du site. D’autres variétés de liquides ont pu être utilisé localement (bière, lait...). Les petits pots ont également pu contenir d'autres types d'offrandes telles que des grains, des fruits, etc., offertes de manière individuelle ou symbolique aux divinités. Sur cette ques- 
tion des contenus, on peut se perdre en conjectures, tant les utilisations peuvent être diverses. "Les tentatives d'identification des fonctions de la vaisselle céramique en contexte de sanctuaire achoppent généralement sur la faiblesse de indices permettant d'éclairer cette réalité. Si [elle] peut être rapprochée sous certains aspects d'autres catégories de mobilier présentes dans les sanctuaires [...], elle s'en différencie par la multiplicité et la complexité des fonctions et utilisations auxquelles elle se prête " (Barral, 2015). Par ailleurs, la variété des rites et des cérémonies d'une région ou d'une communauté à une autre peut également induire des biais dans l'interprétation des modes d'utilisation des vases.

Si l'exposition de viande et la pratique des libations et/ ou d'offrandes alimentaires semblent avérées sur le site de Parc-ar-Groas, rien n'indique que la fosse S. 9 d'une part, et le dépôt de vases d'autre part, soient strictement contemporains et participent d'une même cérémonie. Il peut s'agir d'événements distincts dans le cadre du fonctionnement du sanctuaire dont la durée précise est inconnue. Ces indices semblent cependant caractériser la fonction du lieu, au même titre que la sélection particulière de petits vases. En effet, en dehors des vestiges d'animaux, l'une des particularités définissant un espace votif "réside dans la composition du répertoire céramique, en particulier dans la prépondérance des formes spécifiques au service de la boisson (vases balustres, cruches, gobelets) sur la vaisselle strictement alimentaire " (Poux, 2000). Pour ce qui est des vases, rappelons que "généralement, vaisselle céramique, amphores vinaires [..] ne sauraient être confondu[e]s avec l'offrande elle-même. Ce sont les vestiges des rituels, l'accompagnement utilisé pour le sacrifice et son souvenir, ainsi que pour le banquet et les libations qui l'ont suivi " (Arcelin et Brunaux, 2003, p. 245). Toutefois, il ne s'agit plus obligatoirement des simples récipients profanes puisqu'ils demeurent dans l'enceinte sacrée du sanctuaire. Enfin, il convient de rappeler que les libations peuvent également intervenir dans le domaine funéraire, mais les relations avec la nécropole voisine et son hypothétique pérennité au-delà du premier quart du $\mathrm{II}^{e} \mathrm{~s}$. av. n. è. (date de l'urne peinte) sont inconnues. Rien ne permet, en l'état, d'interpréter le lot de la sorte, d'autant que l'accumulation et la quantité de vases présents semblent excessives dans ce cas.

Reste la question de la datation. Les rejets des vases dans la seconde et dernière phase d'occupation du fossé (T. 2b) placent cette étape à la fin de la phase I. Les dates des différents types de poteries se concentrent sur la première moitié du Ir s. av. n. è. (fig. 26). La présence de quelques modèles de vases et/ou de décors perdurant jusqu’à la fin de ce siècle tendrait à dater l'enfouissement vers le milieu de celui-ci, autour de la fin de l'Indépendance gauloise, sans en tirer de conclusions historiques par rapport à ces événements ou à la guerre des Gaules; d'autant qu'un nouvel aménagement reprenant les mêmes orientations et le même emplacement semble lui succéder rapidement dès l'époque augustéenne (phase II), le fossé T. 1 remplaçant le fossé T. 2 (cf. supra, fig. 3 et 5). Là encore, ces indices de continuité rejoignent ceux observés sur la plupart des sites laténiens quimpérois toujours en fonctionnement au début du i ${ }^{\text {er }}$ s. de n. è. (Le Bihan et Villard, 2012). Malgré tout, l'analyse typologique renvoie parfois certains vases, notamment les gobelets (cf. supra, 3.3.2.), vers des références ou des similitudes plus anciennes (début $\mathrm{II}^{\mathrm{e}} \mathrm{s}$. av. n. è.), mais ceci sans certitude (pérennité ou non de certains modèles). Dès lors, se pose la question du mode d'assemblage du lot. S'agit-il d'un ensemble strictement contemporain lié à une cérémonie de clôture ou d'un rejet d'éléments, plus distincts chronologiquement ( $\mathrm{II}^{\mathrm{e}-}$ $\mathrm{I}^{\text {er }} s$. av. n. è.), récupérés dans l'enceinte du sanctuaire, à l'image des déménagements observés lors des scellements des fossés antiques? L'homogénéité du lot rendrait la première hypothèse séduisante. Toutefois, l'emprise limitée du dépôt et sa concentration ne sont pas suffisantes pour opter en faveur de l'une ou de l'autre. En l'état actuel des connaissances sur les infrastructures gauloises du site, il demeure difficile de trancher et le débat reste ouvert d'autant que la date de fondation et la durée d'occupation du sanctuaire laténien sont inconnues. Il en va de même en ce qui concerne le rythme ou la fréquence des cérémonies et des offrandes à la fin de cette période et donc de la constitution de l'ensemble de poteries.

\section{CONCLUSION}

Le lot de poteries mis au jour dans le fossé T. 2 de Parcar-Groas est intéressant à plus d'un titre puisqu'il permet d'argumenter en faveur de la fonction cultuelle de l'établissement de La Tène finale. Typologiquement, il livre un ensemble remarquable et original. Sa principale particularité réside dans une concentration de près de cent-cinquante récipients de petite taille et de faible contenance pour lesquels l'accumulation et la sélection des modules induisent une fonction et une utilisation spécifiques pouvant être rattachées à une vocation rituelle. Ce lot homogène se caractérise par une réelle diversité des formes tout en conservant un registre ornemental limité et spécifique (moulures, cordons, cannelures). Ces poteries appartiennent au corpus des céramiques bretonnes en usage à la fin de La Tène finale. Par ailleurs, par la nature de son assemblage et son contexte de découverte, ce lot aborde des problématiques à propos de la religion et soulève des questions à propos des pratiques au sein des lieux de culte à la fin de l'époque gauloise, tout en montrant les difficul- 
tés d'interprétation de tels indices. Malheureusement, les conditions de conservation des vestiges de cette époque sont mauvaises (cf. supra, fig. 2 et 6) : arasement par les occupations antiques postérieures, fouilles limitées à une faible partie de l'emprise de l'établissement (entre un quart et un tiers de l'espace interne étudié). Les principales caractéristiques des grands sanctuaires gaulois font défaut : absence d'armements ou de monnaies sacrifiés, de concentration de rejets d'amphores et d'ossements...; absence également, ou pauvreté des structures immobilières évocatrices. La littérature montre toutefois quelques rares exemples d'établissements cultuels se définissant par d'autres critères, notamment les assemblages de vaisselle céramique particuliers (Barral, 2015; Bouvet et al., 2003). Enfin à Parc-ar-Groas, certains indices suggèrent des pratiques sacrificielles et d'offrandes chtoniennes particulières en petites fosses que l'on retrouve également à Mirebeau (cf. supra).

Par ailleurs, le site bénéficie d'une implantation géographique remarquable au cœur d'un réseau d'établissements ruraux, d'une agglomération et de sites fortifiés gaulois, et il matérialise un point de convergence d'itinéraires. Par ces caractéristiques, il remplit les critères présidant à l'aménagement des lieux de culte à l'âge du Fer (Arcelin et Brunaux, 2003). La question du statut du sanctuaire de Parc-ar-Groas, au cours de La Tène finale, au sein de ce territoire dominé par le mont Frugy s'étendant aux plateaux entourant les vallées de l'Odet ou du Steïr reste donc posée; de même que celles de la nature des rituels, collectifs ou individuels, qui y étaient pratiqués, des divinités honorées, etc.

Malgré tout, et en définitive, cette étude de mobilier permet de remonter aux sources de la vocation religieuse de l'établissement de Parc-ar-Groas, vocation qui perdurera et s'affirmera durant l'Antiquité jusqu'au début du haut Moyen Âge. Même limités, les quelques indices identifiés sont importants, compte tenu du manque de sites de référence sur ces problématiques en Bretagne pour cette période. Les vestiges du fossé T.2 de Parc-ar-Groas, et surtout les particularismes et les sélections inhérents au lot de poteries qui leur sont associés, peuvent prendre place dans le cortège des sites à vocation cultuelle de l'extrême fin de l'âge du Fer mis au jour en Armorique et identifiés principalement par la nature du mobilier exhumé. Le site des Haches à Saint-Jacut-de-la-Mer, étudié par Catherine Bizien (1990), tout comme celui de Mez-Notariou à Ouessant (Le Bihan et Villard, 2020; Villard et Le Bihan, 2020), ne livrent que des structures immobilières indigentes et très fortement érodées. Par bien des aspects, Parc-ar-Groas s'intègre aux problématiques d'identification des phases initiales d'un certain nombre de sanctuaires se développant au cours de l'époque gallo-romaine. La densité des aménagements antiques y implique une destruction, parfois irrémédiable, des vestiges les plus anciens, notamment laténiens. De plus, la présence d'artéfacts caractéristiques de ces sites gaulois (ossements animaux, armes...) peut y être plus discrète. En 2016, les conclusions de l'étude du sanctuaire de la Fermerie à Juvigné (Mayenne) dressaient un bilan critique des connaissances sur l'ensemble des installations cultuelles de l'âge du Fer en Grand Ouest (Bossard et al., 2016), mettant en avant de nombreuses incertitudes et la faiblesse de la documentation : érosion anthropique, vestiges immobiliers peu flagrants, variation ou non d'orientation entre établissements gaulois et antiques, accent sur le mobilier métallique au détriment du reste. En ce qui concerne Parc-ar-Groas, "bien que l'hypothèse d'un lieu de culte à La Tène finale ne puisse être totalement exclue, elle est difficile à soutenir à partir [des] seules données ", caractérisées alors par la seule présence des restes animaux de la fosse S. 9. Cette conclusion ne tenait toutefois pas compte d'un certain nombre de paramètres complémentaires tels que l'implantation topographique du site et son riche et dense environnement archéologique contemporain. Par ailleurs, la présence du lot particulier de poteries, demeuré jusqu'ici inédit, ne pouvait être pris en compte dans l'analyse du développement de ce site. Cet ensemble de mobilier renforce donc l'argumentation en faveur d'un établissement cultuel laténien à Parc-ar-Groas. Malheureusement, ces données demeurent limitées car l'urbanisation du secteur réduit l'observation à quelques fenêtres, au détriment d'une vision plus globale du site. Celle-ci aurait été possible au $\mathrm{XIX}^{\mathrm{e}} \mathrm{s}$., lors de l'intervention de René-François Le Men, mais les méthodes d'études d'alors et l'état des connaissances ne le permettaient pas.

Si l'étude des céramiques de Parc-ar-Groas apporte des éléments complémentaires en faveur d'une interprétation de ce site comme lieu de culte de la fin de l'âge du Fer, la nature et l'origine de ce dernier demeurent inconnues. Le bilan régional précédemment évoqué montre que c'est également le cas pour la quinzaine de sites présentés. Seuls ceux livrant un abondant mobilier métallique laténien sont retenus comme possibles sanctuaires gaulois (Bossard et al., 2016). Pour les autres, si des pratiques religieuses sont supposées, quelquefois certifiées, "le cadre des activités demeure mal renseigné, voire inconnu » : privé, public ou communautaire? Le cas du sanctuaire du Chapeau à Neuville-sur-Sarthe (72) montre qu'il s'agissait, dans un premier temps, d'un enclos cultuel dépendant d'un établissement rural limitrophe. Ce dernier disparut rapidement au profit d'un sanctuaire autonome jusqu'au $\mathrm{III}^{\mathrm{e}} \mathrm{s}$. de n. è. (Guillier, 2020).

Aucun signe d'appropriation d'un lieu de culte par une entité à caractère privé n'est perceptible à Parc-ar- 
Groas, bien que des établissements ruraux laténiens et un peuplement assez dense existent à proximité immédiate (souterrain de Parc-ar-Bosser) et dans les environs du site (fermes du Braden). En revanche, il faut sans doute tenir compte de la puissance de ce site. Le sommet du mont Frugy est un marqueur topographique essentiel au sud du plateau de Cornouaille. Le paysage se découvre sur plus de $300 \mathrm{~km}^{2}$. Les grands sites gaulois de Kercaradec et de Kergolvez participent de l'organisation générale d'un territoire au sein duquel ce sommet semble tenir une place privilégiée. Des itinéraires importants s'y rencontrent, probablement depuis la fin du premier âge du Fer (Le Bihan et Villard, 2012). Une nécropole y est implantée depuis le tout début de La Tène.

Au-delà de la simple question religieuse, l'état des vestiges de Parc-ar-Groas et les conditions de leur découverte incitent à réfléchir sur l'ampleur des éléments détruits et des pertes de données sur de tels sites. S'il n'est pas question de les réinventer, il ne faut, ni les négliger, ni les écarter des raisonnements.

\section{Bibliographie}

Aн Thon E. (dir.), 2018, Bretagne, Côtes-d'Armor, Plumaugat, Saint-Pierre. Un vaste établissement de la fin de l'âge $d u$ Fer, rapport de fouille archéologique, Cesson-Sévigné, Inrap Grand Ouest, 429 p.

Ан Thon E. (dir.), 2019, Bretagne, Ille-et-Vilaine, Gévezé, La Croix du Vivier. Occupations laténienne, gallo-romaine et altomédiévale, rapport de fouille archéologique, Cesson-Sévigné, Inrap Grand Ouest, 433 p.

Arcelin P. et Brunaux J.-L., 2003, "Sanctuaires et pratiques cultuelles. L'apport des recherches archéologiques récentes à la compréhension de la sphère religieuse des Gaulois ", dans Arcelin P. et Brunaux J.-L. (dir.), Celtes et sanctuaires en France à l'âge du Fer, Gallia, t. 60, p. 243-247.

BARral P., 2015, "La vaisselle céramique dans les sanctuaires de la fin de l'âge du Fer. Méthodes d'approche et problèmes d'interprétation à partir de l'exemple de Mirebeau-surBèze ", dans Kaurin J., Marion S. et Bataille G. (dir.), Décrire, analyser, interpréter les pratiques de dépôt à l'âge du Fer, Actes de la table ronde de Bibracte, Centre archéologique européen (Glux-en-Glenne, 2-3 février 2012), Glux-enGlenne (Bibracte, 26), p. 41-52.

Bizien C., 1990, Rapport de fouille urgent 1990. Les Haches en Saint-Jacut-de-la-Mer, $30 \mathrm{p}$.

Bossard S., Aubin G. et Meissonnier J., 2016, " Le sanctuaire de la Fermerie à Juvigné (Mayenne), de l'âge du Fer à l'époque romaine ", Gallia, 73-2, p. 25-53.

Bouvet J.-P., Daire M.-Y., Le Bihan J.-P., Nillesse O., Villard-Le Tiec A., Batt M.et Bizien-Jaglin C., 2003,
"La France de l'Ouest (Bretagne, Pays de la Loire) », dans Arcelin P. et Brunaux J.-L. (dir.), Celtes et sanctuaires en France à l'âge du Fer, Gallia, t. 60, p. 75-105.

Brunaux J.-L., 1986, Les Gaulois. Sanctuaires et rites, Paris, Errance (Les Hespérides), $154 \mathrm{p}$.

Brunaux J.-L., 2000, Les religions gauloises. Nouvelles approches sur les rituels celtiques de la Gaule indépendante, Paris, Errance, $272 \mathrm{p}$.

Brunaux J.-L. et MÉniel P., 1983, « Le sanctuaire de Gournay-sur-Aronde (Oise) : structures et rites, les animaux du sacrifice ", dans Bardon L., Durand M., Duval A., Massy J.-L., Rapin A., Robinson C., Woimant G.-P., Blanchet J.-C. et Brunaux J.-L., Les celtes dans le nord $d u$ bassin parisien (VI-ter s. av. J.-C.), actes du Ve colloque tenu à Senlis, Revue archéologique de Picardie, nos 1-2, p. 165-173.

Cherel A.-F., Lierville O. et Menez Y., avec la collaboration de Villard-Le Tiec A., Jean S. et Lorho T., 2018, « Les céramiques gauloises en Bretagne. Évolution des formes et des décors entre le $\mathrm{VI}^{\mathrm{e}}$ et le $\mathrm{I}^{\mathrm{er}}$ s. av. n. è. ", dans Menez Y. (dir.), Céramiques gauloises d'Armorique. Les dessiner, les caractériser, les dater, Rennes, PUR (Archéologie et Culture), p. 253-356.

Cornec J., Le Goff E., Le Guévallou R., Levillayer A., Moreau C., Mortreau M. et Thébaud S., 2018, " La céramique du vi ${ }^{\mathrm{e}}$ au $\mathrm{I}^{\mathrm{er}}$ s. av. n. è. en Pays de la Loire : évolution des formes, des décors et mobiliers associés ", dans Menez Y. (dir.), Céramiques gauloises d'Armorique. Les dessiner, les caractériser, les dater, Rennes, PUR (Archéologie et Culture), p. 357-450.

DAIre M.-Y., 1992, Les céramiques armoricaines de la fin de l'âge $d u$ Fer, Travaux du laboratoire d'anthropologie no 39, université de Rennes I, 313 p.

Daniel A., 1982, Quimper, Parc-ar-Groas, rapport de fouille, Rennes, SRA de Bretagne.

Dizoт Lieutenant, 1896, « Rapport sur la découverte d'objets et d'habitations de la période gallo-romaine, par le $118^{\mathrm{e}}$ régiment d'infanterie, en son terrain de manœuvre du mont Frugy, en 1896 ", Bulletin de la Société archéologique du Finistère, t. XXIII, p. 235-240.

Dizot Lieutenant, 1897, "Plan des fouilles du Champ de Manœuvre ", Bulletin de la Société archéologique du Finistère, t. XXIV, p. 40-41.

Durand J.-C. (dir.), 2017, Bretagne, Ille-et-Vilaine, Erbrée "La Huperie ». Un établissement agricole du second âge du Fer, rapport de fouille archéologique, Cesson-Sévigné, Inrap Grand Ouest, 414 p.

FAuduet I., 2020, "Fait religieux et pratiques cultuelles en Gaule romaine. Que révèlent les témoignages archéologiques ", Les Nouvelles de l'archéologie, 160, p. 20-25.

Faulon M.-N., 1994, Les céramiques du Braden I en Quimper (Finistère). Un habitat armoricain de La Tène finale, mémoire de maîtrise d'histoire de l'Art et d'Archéologie 
sous la direction de P. Ballet et M.-Y. Daire, université de Rennes II, 165 p.

Galliou P., 1984, "Une bague mérovingienne mise au jour à Quimper", Archéologie en Bretagne no 31, p. 41-44.

Giot P.-R., 1978, "L'urne cinéraire peinte du mont Frugy à Quimper (Finistère) ", Études celtiques, no 29, vol. XV, fasc. 2, p. 491-494.

Giot P.-R., Briard J. et Pape L., 1979, Protohistoire de la Bretagne, Rennes, Édilarge, Éditions Ouest-France, 437 p.

Goussard É., Lambot B., Pieters M. et Squevin B., 2019, "Le phénomène des dépôts de miniatures d'armes dans les sanctuaires celtes. Réflexions à partir de l'exemples des Rèmes ", dans Barral P. et Thivet M. (dir.), Sanctuaires de l'âge du Fer. Actualités de la recherche en Europe celtique occidentale, actes du 41e colloque de l'AFEAF (Dole, 25-27 mai 2017), Paris, AFEAF (Afeaf, 1), p. 313-330.

Guillier G. (dir.), 2020, Le sanctuaire du Chapeau (Neuvillesur-Sarthe). Évolution d'un complexe cultuel en territoire cénoman du II s. av. J.-C. au III s. apr. J.-C., Paris, Inrap/ CNRS éditions (Recherches archéologiques, 19), 301 p.

Le Bihan J.-P., 1990a, "Quimper, Parc-ar-Groas », dans GaLLiou P. et Le Bihan J.-P., "Chronique d'archéologie antique et médiévale ", Bulletin de la Société archéologique du Finistère, t. CXIX, p. 118-124.

Le Bihan J.-P., 1990b, Quimper Keradennec. Opération d'évaluation et de diagnostic lourd, DFS, Rennes, SRA de Bretagne, $32 \mathrm{p}$.

Le Bihan J.-P., 1995, Le sanctuaire gaulois et gallo-romain de Parc-ar-Groas à Quimper, DFS, Rennes, SRA de Bretagne, $242 \mathrm{p}$.

Le BiHAN J.-P., 1996, Les abords du sanctuaire gaulois et galloromain de Parc-ar-Groas à Quimper, DFS, Rennes, SRA de Bretagne, 8 p., 5 fig., $3 \mathrm{cl}$.

Le Bihan J.-P., 1997, Les vestiges archéologiques des Hauts-dePenvillers à Kerfeunteun (Quimper-Finistère), DFS, Rennes, SRA de Bretagne, $106 \mathrm{p}$.

Le Bihan J.-P., 1998a, Sépultures de l'âge du Fer et vestiges gallo-romains dans le sanctuaire de Parc-ar-Groas à Quimper : Parc-ar-Groas V, DFS, Rennes, SRA de Bretagne, $34 \mathrm{p}$ (texte et figures).

LE Bihan J.-P., 1998b, Vestiges gallo-romains de sanctuaire sur les pentes du mont Frugy à Quimper, 77 rue du Frugy, DFS, Rennes, SRA de Bretagne, 13 p., 12 fig.

Le Bihan J.-P. (dir.), 2007, Vestiges médiévaux et modernes place Bérardier à Quimper (Finistère), Rapport de diagnostic archéologique, Rennes, SRA de Bretagne, 2 volumes.

Le Bihan J.-P. avec la collaboration de Carrie P., Goupil F., Menez Y., 1984, Villages gaulois et parcellaires antiques au Braden à Quimper. Une recherche en milieu périurbain, Cahiers de Quimper antique $n^{\circ} 1$, Centre d'étude et de Recherche Archéologique de Quimper, 264 p.

Le Bihan J.-P., Daire M.-Y., Carrie P. et Goupil F., 1987,
"Le hameau du Braden II à Quimper (Finistère) ", Revue archéologique de l'Ouest, 4, p. 67-89.

Le Bihan J.-P. et Villard J.-F., 2005, Archéologie de Quimper : matériaux pour servir l'Histoire, t. 1 : De la chute de l'Empire romain à la fin du Moyen Âge, Saint-Thonan, éd. Centre de recherche archéologique du Finistère/Cloitre, 460 p (178 fig. et 232 clichés).

Le Bihan J.-P. et Villard J.-F., 2010, Archéologie d'une île à la pointe de l'Europe: Ouessant, t. 2 : L'habitat de Mez-Notariou des origines à l'âge du Bronze, Quimper, Centre de recherche archéologique du Finistère/éditions Cloître, 595 p.

Le Bihan J.-P. et Villard J.-F., 2012, Archéologie de Quimper : matériaux pour servir l'histoire, t. 2 : Au temps de l'Empire romain, Saint-Thonan, éd. Centre de recherche archéologique du Finistère/Cloître, 848 p (325 fig. et 417 clichés).

Le Bihan J.-P. et Villard J.-F., avec les contributions de Clavel B. et MÉniel P., 2020, Archéologie d'une île à la pointe de l'Europe: Ouessant, t. 3, vol. 1 : L'agglomération de MezNotariou du Bronze final III aux débuts de l'époque gauloise, évolutions et mutations. Vestiges et histoire, Quimper, Centre de recherche archéologique du Finistère, 336 p.

Le Gall V. (dir.), 2015, MENEAC (Morbihan). La ferme laténienne du Val Bodron, rapport de fouille archéologique, Cesson-Sévigné, Inrap Grand Ouest, 263 p.

Le Gall V. et Paranthoën A.-S., 2020, Pluguffan, Ti Lipig (Finistère). Une longue occupation : du Néolithique au Moyen Âge, rapport de fouille archéologique, Cesson-Sévigné, Inrap Grand Ouest, 495 p.

Le Goff E. (dir.), 2014, Bretagne, Finistère, Quimper (29232). L'agglomération gauloise de Kergolvez sous le contournement nord-ouest de Quimper, rapport de fouille archéologique, Cesson-Sévigné, Inrap Grand Ouest, 2 volumes.

Le Men R.-F., 1875-1876, «Fouilles d'un poste gallo-romain sur le mont Frugy, à Quimper ", Bulletin de la Société archéologique du Finistère, t. III, p. 179-199.

Menez Y., 2008, Le Camp de Saint-Symphorien à Paule (Côtes-d'Armor) et les résidences de l'aristocratie du second âge du Fer en France septentrionale, thèse sous la direction d'O. Buchsenschutz, université de Paris I, Panthéon Sorbonne, UFR d'Archéologie, 2 volumes.

MÉniel P., 2016, «Les restes animaux du sanctuaire gaulois et antique de Mirebeau-sur-Bèze (Côte-d'Or) (fouilles 20012007) ", Gallia 73.2, p. 55-80.

Nicolas É., 2013, Quimper, Finistère. Kervouyec II, De multiples occupations protohistoriques, rapport final d'opération de fouille archéologique, Cesson-Sévigné, Inrap Grand Ouest, 308 p.

Nicolas É. et Villard J.-F., 2019, Finistère, Quimper. Les vestiges du sanctuaire antique de Parc-ar-Groas au 83 bis rue du Frugy, rapport de fouille archéologique, Cesson-Sévigné, Inrap Grand Ouest, 225 p.

PAPE L., 1978, La civitas des Osismes à l'époque gallo-romaine, 
Paris, éditions Klincksieck, 541 p.

Poux M., 2000, "Espaces votifs, espaces festifs. Banquets et rites de libation en contexte de sanctuaires et d'enclos ", Revue archéologique de Picardie, $\mathrm{n}^{\mathrm{os}} 1-2$, Les enclos celtiques - Actes de la table ronde de Ribemont-sur-Ancre (Somme), p. 217-231.

Poux M. et Demierre M. (dir.), 2015, Le sanctuaire de Corent (Puy-de-Dôme, Auvergne). Vestiges et rituels, Gallia, 62 ${ }^{\mathrm{e}}$ supplément, Paris, CNRS éditions, 707 p.

TAnguy B., 1995, "Entre légende et histoire ( $\mathrm{v}^{\mathrm{e}}-\mathrm{XI}^{\mathrm{e}}$ s.) ", dans Histoire de Quimper, Toulouse, éditions Privat/Société archéologique du Finistère, p. 41-54.

Tanguy D., 2006, Kerven Teignouse, un habitat de l'âge du Fer (Inguiniel, Morbihan), Programme triennal 2004-2006, SRA de Bretagne, $82 \mathrm{p}$.

TAnguy D., 2011, Kerven Teignouse, un habitat de l'âge du Fer (Inguiniel, Morbihan), Programme 2010-2012, rapport intermédiaire 2011, SRA de Bretagne, 32 p.

Villard J.-F., 2012a, "Poteries et terres cuites », dans Le Bihan J.-P. et Villard J.-F., Archéologie de Quimper : matériaux pour servir l'Histoire, t. 2 : Au temps de l'Empire romain, Saint-Thonan, CRAF/Cloître, p. 532-555.
Villard J.-F., 2012b, «Catalogue raisonné des céramiques gallo-romaines ", dans Le Bihan J.-P. et Villard J.-F., Archéologie de Quimper : matériaux pour servir l'Histoire, t. 2 : Au temps de l'Empire romain, Saint-Thonan, CRAF/Cloître, p. 746-844.

Villard J.-F., 2016a, Quimper, 83 rue du Frugy (29). Voirie autour du sanctuaire antique de Parc-ar-Groas, rapport de fouille, Cesson-Sévigné, Inrap Grand Ouest, 100 p.

VIllard J.-F., 2016b, Quimper, 83 bis rue du Frugy (29). Limites méridionales et environnement du sanctuaire antique de Parc-ar-Groas, rapport de fouille, Cesson-Sévigné, Inrap Grand Ouest, $101 \mathrm{p}$.

Villard J.-F., Le Bihan J.-P., Pluton S. et Gaumé É, 2006, "La nécropole à crémations du Hallstatt final-La Tène ancienne de Kerjaouen en Quimper (Finistère) ", Revue archéologique de l'Ouest, 23, p. 171-198.

Villard J.-F. et Le Bihan J.-P., avec la contribution de Robic J.-Y., 2020, Archéologie d'une île à la pointe de l'Europe : Ouessant, t. 3, vol. 2 : L'agglomération de Mez-Notariou du Bronze final III aux débuts de l'époque gauloise, évolutions et mutations. Étude du mobilier, Quimper, Centre de recherche archéologique du Finistère, 652 p.

\section{El depósito de cerámica gala del santuario latino de Parc-ar-Groas en Quimper (Finistère)}

Descubierto en 1990, el depósito de cerámicas galas del santuario de Parc-ar-Groas (Quimper) ha permanecido inédito, ya que las numerosas publicaciones sobre el yacimiento tratan principalmente de su desarrollo en época romana. Se han podido reconstruir una treintena de perfles completos de pequeños vasos y cuencos, junto a los fragmentos de un centenar de recipientes. Todos proceden del relleno de un tramo de un mismo foso. La concentración de un gran número de vasijas, caracterizadas por su pequeño tamaño, ofrece una buena muestra de este tipo de recipientes utilizados al final de la última fase de La Tène. Por su tipología, no difieren de los hallados en los hábitats cercanos, pero el número reducido de tipos parece corresponder a una vajilla de uso especifico. Esto abre nuevas perspectivas y permite plantear cuestiones sobre su utilización en el marco de actividades rituales llevadas a cabo en el yacimiento (libaciones, ofrendas).

Palabras clave: actividades rituales, Edad del Hierro, cerámica, depósito, La Tène final, religión, santuario. 